DOI: $10.24850 /$ j-tyca-2021-02-04

Artículos

\title{
Uso de suelo y su efecto en el escurrimiento modelado con SWAT
}

\section{Land use and its effect on runoff modeled with SWAT}

Brenda Cruz-Arévalo1, https://orcid.org/0000-0003-3823-9781

Francisco Gavi-Reyes (EPD)², https://orcid.org/0000-0001-5854-6274

Mario Martínez-Menez (EPD) ${ }^{3}$

Juan Juárez-Méndez ${ }^{4}$

${ }^{1}$ Colegio de Postgraduados, Campus Montecillo, Texcoco, Estado de México, México, cruz.arevalo28@gmail.com

${ }^{2}$ Colegio de Postgraduados, Campus Montecillo, Texcoco, Estado de México, México

${ }^{3}$ Colegio de Postgraduados, Campus Montecillo, Texcoco, Estado de México, México

${ }^{4}$ Universidad Autónoma Chapingo, Departamento de Suelos, km 38.5 Carretera México-Texcoco Chapingo, Estado de México, México, jjuarezm@taurus.chapingo.mx

Autora para correspondencia: Brenda Cruz-Arévalo, cruz.arevalo28@gmail.com 


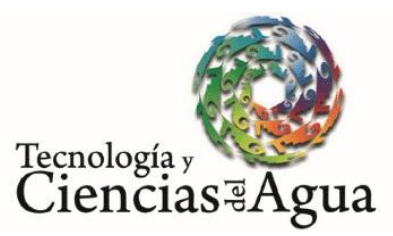

2021, Instituto Mexicano de Tecnología del Agua

Open Access bajo la licencia CC BY-NC-SA 4.0

(https://creativecommons.org/licenses/by-nc-sa/4.0/)

\section{Resumen}

La importancia de los modelos de simulación para el monitoreo de los recursos naturales cada vez es mayor. El objetivo del presente estudio fue aplicar el modelo SWAT (Soil Water Assessment Tool) para evaluar el impacto del cambio de uso de suelo sobre el escurrimiento y los sedimentos en la cuenca del río Chapingo de 1999 a 2015. Se generaron dos mapas de uso de suelo mediante la fotointerpretación de imágenes Landsat y RapidEye, con resoluciones de 15 y $5 \mathrm{~m}$, respectivamente, y recorridos de campo para verificación. Ante la falta de datos de escurrimiento confiable y reciente se utilizaron los registros mensuales de los periodos 1964-1970 y 1971-1975 para la calibración y validación del modelo. En este proceso, los coeficientes de Nash-Sutcliffe fueron de 0.58 y 0.52 , respectivamente. El uso de suelo de la cuenca en el periodo de estudio cambió: agricultura (-6.9\%); zona urbana $(+2.89 \%)$; área de minería (+5.04 \%), y pastizal (+7.75\%). La aplicación del SWAT calibrado y validado sólo para escurrimiento para el periodo 1999-2015 no detectó cambios en el escurrimiento ( $p=0.2351)$ y sedimentos ( $p=$ 0.4430) en función del cambio de uso de suelo determinado. La correlación entre el escurrimiento y los sedimentos anuales simulados con SWAT fue significativa ( $p=0.0116$ ), con un $R^{2}$ bajo $(0.36)$, atribuible a la falta de datos de campo de sedimentos para calibrar y validar el SWAT, además de la presencia de acciones de conservación de suelo y agua en la cuenca estudiada.

Palabras clave: cambio de uso del suelo, sensores remotos, modelación hidrológica, escurrimiento superficial, SWAT, SWAT-CUP. 


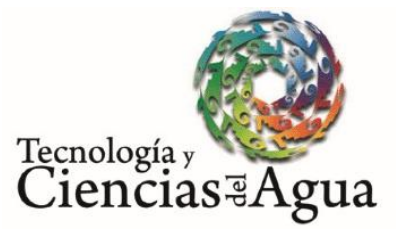

2021, Instituto Mexicano de Tecnología del Agua

Open Access bajo la licencia CC BY-NC-SA 4.0

(https://creativecommons.org/licenses/by-nc-sa/4.0/)

\section{Abstract}

The importance of simulation models for the monitoring of natural resources is increasing. The objective of this study was to apply the SWAT model (Soil Water Assessment Tool) to evaluate the impact of land use change on runoff and sediments in the Chapingo River basin from 1999 to 2015. Two land use maps were generated through the photointerpretation of Landsat and RapidEye images with resolutions of 15 and $5 \mathrm{~m}$, respectively and field trips for verification. In the absence of reliable and recent runoff data, the monthly records for the periods 19641970 and 1971-1975 were used for the calibration and validation of the model. In this process the Nash-Sutcliffe coefficients were 0.58 and 0.52 , respectively. The land use of the basin in the study period changed: agriculture (-6.9\%); urban area (+ $2.89 \%)$; mining area $(+5.04 \%)$, and pasture $(+7.75 \%)$. The application of SWAT calibrated and validated only for runoff for the period 1999-2015 did not detect changes in runoff ( $p=0.2351)$ and sediments $(p=0.4430)$ depending on the change in land use determined. The correlation between runoff and annual sediments simulated with SWAT was significant $(p=0.0116)$ with a low $R^{2}(0.36)$, attributable to the lack of sediment field data to calibrate and validate the SWAT, in addition to the presence of soil and water conservation practices in the basin studied.

Keywords: Change in land use, remote sensing, hydrological modeling, surface runoff, SWAT, SWAT-CUP. 


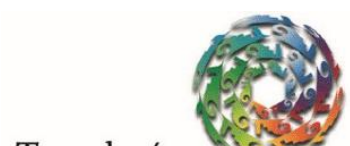

Tecnología y

Ciencias $₫$ Agua

Recibido: 16/05/2019

Aceptado: $28 / 06 / 2020$
2021, Instituto Mexicano de Tecnología del Agua

Open Access bajo la licencia CC BY-NC-SA 4.0

(https://creativecommons.org/licenses/by-nc-sa/4.0/)

\section{Introducción}

Los ecosistemas terrestres han sufrido grandes transformaciones, entre otras causas, debido a la conversión de la cobertura del terreno, y a la degradación e intensificación del uso del suelo. El suelo es un recurso natural con una importancia ambiental infinita, a pesar de esto, el uso inadecuado de éste es muy común, principalmente en México, y es más vulnerable a la erosión, por las características geográficas del país (Bocco, Mendoza, \& Masera, 2001).

En México, durante las últimas cinco décadas se ha intensificado el cambio de cobertura/uso del suelo, cuya tasa de cambio en general está por arriba de la media mundial en materia de deforestación, incremento de las áreas de cultivo, pastoreo y uso urbano, entre otras (Mas et al., 2004). La FAO (2004) indica que México ocupa uno de los primeros lugares en tasa de deforestación en el mundo, con una tasa de 775800 ha/año. 


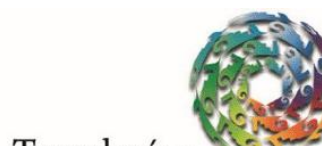

Tecnología y

Ciencias $₫$ Agua
2021, Instituto Mexicano de Tecnología del Agua

Open Access bajo la licencia CC BY-NC-SA 4.0

(https://creativecommons.org/licenses/by-nc-sa/4.0/)

Las consecuencias de los cambios de uso del suelo son preocupantes, ya que impactan directamente en la biodiversidad; en el cambio climático local y regional; en la degradación del suelo; alteran los servicios ecosistémicos (soporte, provisión, regulación y culturales), y afectan la capacidad de los sistemas biológicos para sustentar las necesidades humanas (Lambin, Geist, \& Rindfuss, 2006; Cruz-Huerta, González-Guillén, Martínez-Trinidad, \& Escalona-Maurice, 2015; López, Balderas, Chávez, Pérez, \& Gutiérrez, 2015).

La dinámica de uso del suelo de una cuenca está determinada por las actividades de la población que habita en ella, y repercute de manera directa y casi inmediata en el comportamiento de los escurrimientos superficiales. Asimismo, el estado de la cobertura vegetal dentro de la cuenca, especialmente en la parte alta, es de gran relevancia pues de ello depende el comportamiento y la disponibilidad temporal del recurso hídrico en la parte baja (Miranda, 2008).

Las herramientas computacionales orientadas al estudio de los recursos naturales cada día se mejoran y adquieren mayor importancia, sobre todo para la vegetación, suelo y agua. Entre ellas destacan la geomática, la percepción remota y los sistemas de información geográfica (Camacho-Sanabria, Juan-Pérez, \& Pineda-Jaimes, 2015; López et al., 2015; Morales-Hernández, Carrillo-Gonzales, Zarfán-Molina, \& CornejoLópez, 2016), que son de gran ayuda para llevar a cabo el análisis espacio-temporal de los cambios de uso del suelo, y su efecto en la producción de escurrimientos superficiales y subterráneos, siempre y cuando exista información hidrométrica apropiada.

La escasa infraestructura hidrométrica que tiene México para la medición de caudales podría ser superada mediante la simulación 


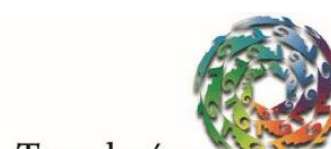

Tecnología y

Ciencias $₫$ Agua
2021, Instituto Mexicano de Tecnología del Agua

Open Access bajo la licencia CC BY-NC-SA 4.0

(https://creativecommons.org/licenses/by-nc-sa/4.0/)

hidrológica, a fin de generar información numérica suficiente sobre cuencas. Esta técnica hace posible el estudio del impacto de los cambios en el uso de suelo sobre los componentes del balance hidrológico. En teoría, un modelo de simulación, entre más detallado sea y más variables considere, generará los resultados más cercanos a la realidad.

Existen diversos modelos hidrológicos que ayudan a la simulación de escenarios de cambio de uso del suelo (Mattos, Parodi, \& Damiano, 2010; Vargas-Castañeda, Ibáñez-Castillo, \& Arteaga-Ramírez, 2015). Uno de dichos modelos es la herramienta de estudio del suelo y agua, conocida como SWAT (Soil Water Assessment Tool, por sus siglas en inglés), diseñada para simular los efectos de la gestión del agua y el movimiento de sedimentos en cuencas rurales.

El SWAT, modelo aplicado en la presente investigación, es una herramienta de modelación hidrológica desarrollado por el Dr. Jeff Arnold de la Universidad de Texas para el Servicio de Investigación Agrícola del Departamento de Agricultura de EUA, conocido como ARS-USDA, por sus siglas en inglés (Neitsch, Arnold, Kiniry, \& Williams, 2009), que permite simular la generación de escurrimiento y sedimentos en cuencas hidrográficas, así como el efecto que tienen las prácticas agronómicas, incluyendo el uso de pesticidas, fertilizantes y derivados biológicos, sobre la calidad del agua de tales cuencas (Behrends et al., 2011).

Dicho modelo divide la cuenca hidrográfica en subcuencas, lo cual es muy útil, en particular cuando hay diversas áreas de la misma cuenca que se ven afectadas por el uso de suelos, de tal forma que impactan grandemente la hidrología del sector. Asimismo, toma en cuenta la variabilidad espacial de la topografía, el uso de la tierra y el tipo de suelo, con el fin de representar la captación en unidades de respuesta hidrológica 


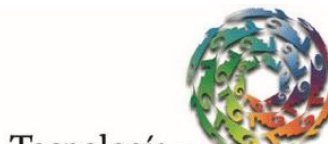

Tecnología y

Ciencias $\stackrel{\Xi}{\unlhd}$ gua
2021, Instituto Mexicano de Tecnología del Agua

Open Access bajo la licencia CC BY-NC-SA 4.0

(https://creativecommons.org/licenses/by-nc-sa/4.0/)

(URH) múltiples. La simulación considera el ciclo hidrológico, el cual controla la cantidad de agua; sedimentos, nutrientes y pesticidas al canal principal en cada subcuenca; y la ruta del caudal que define el movimiento del agua, sedimentos, etcétera, a través de la red de canales de la cuenca hidrográfica hacia el sitio de descarga (Neitsch et al., 2009).

La calibración de modelos hidrológicos se lleva a cabo de forma manual o automatizada. El SWAT usa el programa de calibración e incertidumbre conocido como SWAT-CUP (por sus siglas en inglés, Calibration and Uncertainty Programs for SWAT). Varios estudios sugieren que para un mejor resultado en el análisis de incertidumbre en la modelación hidrológica con SWAT es conveniente utilizar el algoritmo de ajuste de incertidumbre secuencial (SUFI-2) dentro de SWAT-CUP (Almeida, Pereira, \& Pinto, 2018; Brouziyne, Abouabdillah, Bouabid, Benaabidate, \& Oueslati, 2017; Abbaspour, Vaghefi, \& Srinivasan, 2018; Ercan, Goodall, Castronova, Humphrey, \& Beekwilder, 2014).

El SWAT se ha aplicado en varias cuencas del mundo. Teklay, Dile, Setegn, Demissie y Asfaw (2019) usaron el SWAT para evaluar los impactos del cambio del uso de suelo en las respuestas hidrológicas, tales como escorrentía, evapotranspiración y flujo máximo, en la cuenca de Gummara, Etiopía. Lavagnoli, Schwamback y Rigo (2018) evaluaron la sensibilidad de los parámetros de entrada en el modelo SWAT utilizando el modelado del caudal mensual promedio en la cuenca del río Jucu, Espírito Santo, Brasil. Rodrigues et al. (2017) calibraron y validaron el modelo SWAT en la subcuenca del río São Francisco, Brasil. Zhang, Fan, Li y Yi (2017) determinaron la influencia de los patrones de uso del suelo en la erosión en la cuenca de Liusha, China. Salas-Martínez, IbáñezCastillo, Arteaga-Ramírez, Martínez-Menes y Fernández-Reynoso (2014) 
calibraron y validaron el modelo hidrológico SWAT para usarse como herramienta de predicción mensual de la producción de biomasa, escurrimientos y sedimentos en la cuenca del río Mixteco en Oaxaca, México.

El cambio de uso de suelo intensificado en las recientes décadas puede incrementar los escurrimientos y, con ello, degradar los recursos naturales, por lo que su cuantificación es relevante mediante modelos de simulación que también pueden subsanar la escasez de datos de campo. Por tanto, el objetivo de esta investigación fue realizar un análisis del cambio de uso de suelo a través de fotointerpretación de dos imágenes de satélite para el periodo de 1999 a 2011 y determinar su efecto en el escurrimiento de la cuenca del río Chapingo, mediante la aplicación del SWAT.

\title{
Materiales y métodos
}

\author{
Descripción de la cuenca
}


El estudio se realizó en la cuenca del río Chapingo, la cual pertenece a la Vertiente Oriental del Valle de México o Cuenca del Exlago de Texcoco, que a su vez forma parte de la gran Cuenca de México (Figura 1). Tiene una superficie de 1923.42 ha, delimitada por altitudes de 2250 a 3580 msnm, y coordenadas extremas de $19.4929^{\circ} \mathrm{N}, 98.8855^{\circ} \mathrm{W}, 19.4228^{\circ}$ $\mathrm{N}$ y $78.7615^{\circ} \mathrm{W}$ (Márquez, 2013). La precipitación media anual es de 608 $\mathrm{mm}$ y la temperatura del aire de $16.14^{\circ} \mathrm{C}$. La geología está conformada por rocas ígneas y mayoritariamente (69 \%) rocas sedimentarias, como lo son la andesita y brecha sedimentaria, respectivamente (INEGI, 2018). Los tipos de suelos son andosol, leptosol, cambisol y phaeozem; este último ocupa la mayor superficie (41\%) (Ojeda, 2001). Con base en el sistema de Koppen, modificado por Enriqueta García, la cuenca del río Chapingo presenta cuatro unidades de clima: $C(E)(w 2)(w), C(w 0)(w)$, $C(w 1)(w)$ y $C(w 2)(w)$. En la cuenca existen tres zonas de relieves importantes: la parte baja, delimitada por la curva de nivel que pasa por la estación de aforo a una altitud de $2250 \mathrm{msnm}$, y las áreas agrícolas y urbanas (2 $300 \mathrm{msnm}$ ); la zona media o de transición, ubicada entre los 2300 y 2600 msnm, en la cual se implementaron los programas de recuperación de suelos y reforestaciones; y el área de montañas, a una altitud mayor de 2600 msnm (INEGI, 2018). 


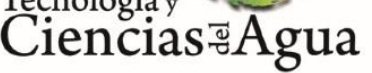

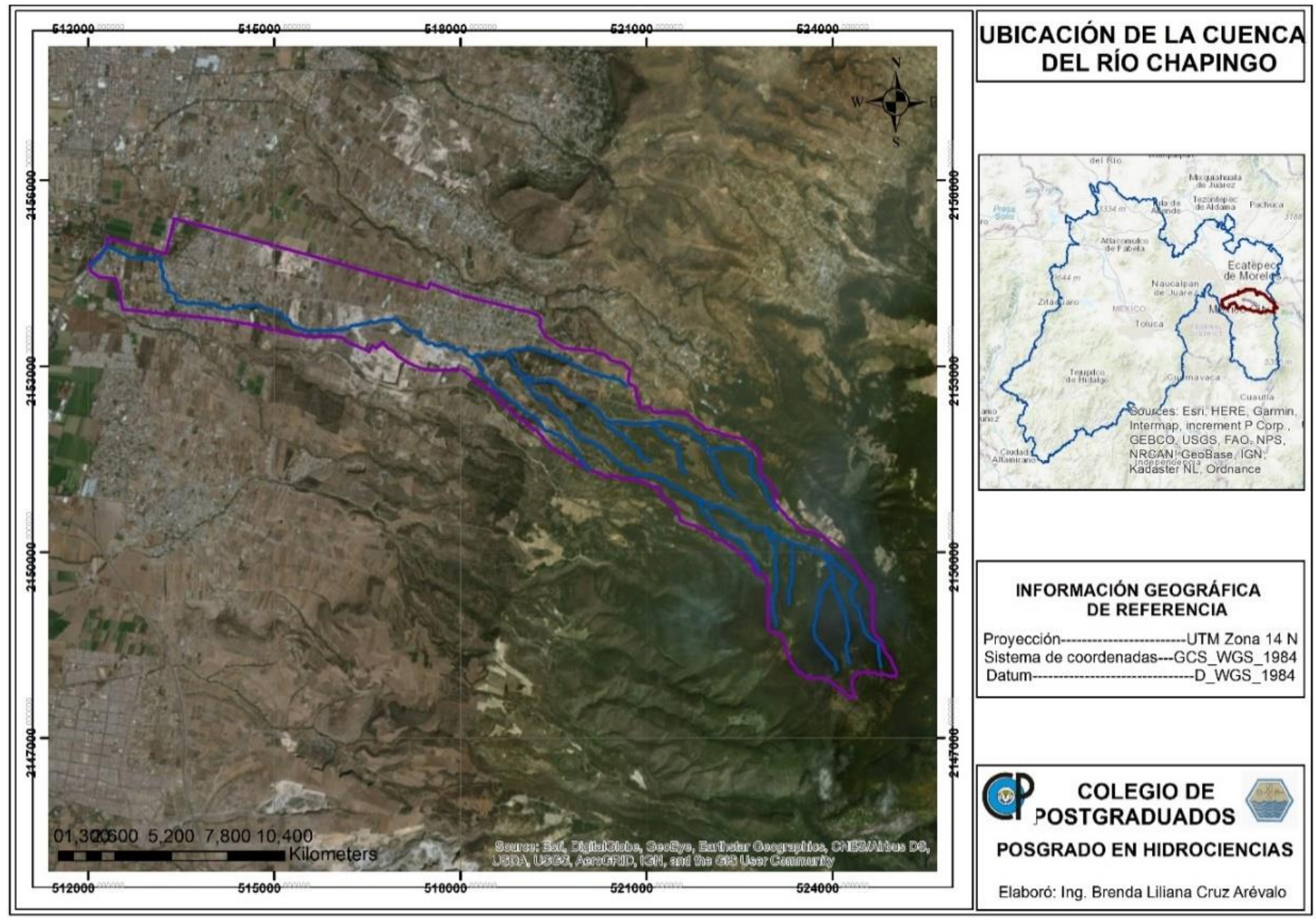

Figura 1. Localización del área de estudio.

\section{Análisis del cambio de uso de suelo}




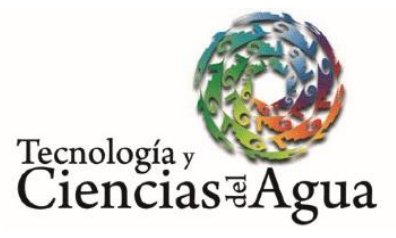

\section{Procesamiento de datos de satélite}

El cambio de uso de suelo se determinó mediante dos imágenes de satélite, una Landsat TM de 1999 y la segunda RapidEye de 2011, ambas del mes de marzo. La imagen Landsat se descargó del portal de USGS (USGS, 2018), mientras que la imagen RapidEye de la plataforma de Planet (Planet, 2018). Fueron referenciadas en sistema de coordenadas UTM zona 14, con datum WGS1984.

La elaboración de los mapas de uso de suelo y vegetación se hizo mediante el proceso de fotointerpretación, en donde la digitalización de los polígonos de usos de suelo se basó en la distribución de los elementos textura, tono y forma, a una escala de 1:1000. Primero se fotointerpretó la imagen del 2011, ya que ésta tenía mayor información, posteriormente los polígonos se sobrepusieron sobre la imagen Landsat de 1999 para delimitar los usos de suelo que presentaron algún cambio (Gordillo-Ruiz \& Castillo-Santiago, 2017).

Se utilizaron imágenes del servidor de Gooogle Earth como apoyo a la fotointerpretación, así como recorrido de campo. En cada sitio visitado se recabó información georreferenciada del uso de suelo y tipo de vegetación; los puntos de verificación en el recorrido de campo se establecieron con base en la duda de algunas tonalidades dentro de las imágenes de satélite y se eligieron 35 puntos. 


\section{Detección de cambios}

Para evaluar los cambios en las coberturas y usos de suelo ocurridos en el periodo 1999-2011 de la cuenca del río Chapingo, se determinaron las tasas de cambio a partir de las superficies obtenidas de cada categoría mediante la fórmula de Palacio-Prieto et al. (2004):

$T d=\left(\left(\frac{S 2}{S 1}\right)^{\frac{1}{n}}-1\right) * 100$

Donde $T d$ es la tasa de cambio anual (\%); S1, el área cubierta al inicio del periodo (ha); $S 2$, el área cubierta al final del periodo (ha), y $n$ es el número de años del periodo.

\section{Análisis de NDVI}

La diferencia del vigor de la vegetación entre el inicio y el final del periodo 1999-2011 se determinó con el Índice de Vegetación de Diferencia Normalizada (NDVI, por sus siglas en inglés), el cual se basa en el 
comportamiento radiométrico de la vegetación, relacionado con la actividad fotosintética y la estructura foliar de las plantas (MenesesTovar, 2011). Esto se realizó para verificar las diferencias entre dos escalas de tiempo.

En el cálculo del NDVI de las imágenes Landsat y RapidEye se utilizó la calculadora de capas raster (Raster calculator), disponible en la herramienta de Análisis Espacial (Spatial Analys Tool) disponible en ArcMap 10.4 (ESRI, 2018). En la ventana que abre esta herramienta se agregaron las capas de acuerdo con las siguientes fórmulas:

Para la imagen Landsat:

$N D V I=\frac{\text { float }(\text { Banda } 4-\text { Banda } 3)}{\text { float }(\text { Banda } 4+\text { Banda } 3)}$

Para la imagen RapidEye:

$N D V I=\frac{\text { float }(\text { Banda } 5-\text { Banda } 3)}{\text { float }(\text { Banda } 5+\text { Banda } 3)}$

Los valores de NDVI obtenidos fueron asignados a los polígonos de uso de suelo y vegetación por medio del cálculo de estadísticas por zonas, o el cálculo de estadísticas zonales ejecutando el módulo "Zonal Statistics as Table" de ArcMap 10.4. 


\title{
Modelación hidrológica con SWAT
}

\author{
Configuración de datos de entrada
}

\section{Modelo de elevación digital}

La delimitación de la cuenca del río Chapingo se hizo con el modelo de elevación digital generado de una imagen LiDAR (Light Detection and Ranging, por sus siglas en inglés) con resolución de cinco metros, descargada de la página del Instituto Nacional de Estadística, Geografía e Informática (INEGI, 2018).

\section{Uso de suelo y vegetación}


La capa vectorial de usos de suelos, generado a partir de dos imágenes, se pasó a archivo raster para ser procesado por SWAT. Las nueve categorías de usos de suelo determinadas se reclasificaron de acuerdo con la base de datos del modelo antes referido (Tabla 1 ).

Tabla 1. Clasificación de los usos de suelo y vegetación de acuerdo con SWAT.

\begin{tabular}{lcc}
\hline Categoría & Clasificación SWAT & Clave SWAT \\
\hline Agricultura & Maíz & CORN \\
Bosque cultivado & Bosque de deciduos & FRSD \\
Bosque de oyamel & Pino & PINE \\
Bosque de pino-encino & Pino & PINE \\
Bosque de encino & Encino & OAK \\
Pastizal & Sideoats grama & SIDE \\
Minas & Suelo desnudo & SUDE \\
Cuerpos de agua & Agua & WATR \\
Urbano & Zona urbana de alta densidad & URML \\
\hline
\end{tabular}

\section{Suelos}




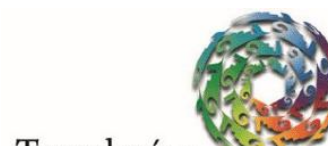

Tecnología y

Ciencias $₫$ Agua
2021, Instituto Mexicano de Tecnología del Agua

Open Access bajo la licencia CC BY-NC-SA 4.0

(https://creativecommons.org/licenses/by-nc-sa/4.0/)

El SWAT cuenta con una base de datos de los diferentes tipos de suelos presentes en EUA, por lo que se tuvo que crear una base de datos propia con los suelos correspondientes al área de estudio. Los tipos de suelos y sus características físicas y químicas se obtuvieron de la investigación de Márquez (2013).

Las variables requeridas por el modelo son: número de capas del perfil (NUMLAYER), espesor de cada capa (Z), grupo hidrológico (HRDGRP), densidad aparente (BD), capacidad de agua disponible en la capa del suelo (AWC), conductividad hidráulica $(K)$, contenido de carbono orgánico (CBN), \% de arcilla (CLAY), \% de arena (SAND), \% de limo $(\mathrm{SLT})$, contenido de rocas (ROCK), albedo (ALB) y valor de $\mathrm{K}$ de la Ecuación Universal de Pérdida de Suelos, conocidas por sus iniciales EUPS (USLEK).

El grupo hidrológico para cada suelo se clasificó de acuerdo con su clase textural. El factor $\mathrm{K}$ de la EUPS se determinó para la primera capa de los perfiles con ayuda del nomograma (Figura 2) para la determinación de la erosionabilidad del suelo (adaptado por Wischmeier \& Smith, 1978). 


\section{Ciencias $₫$ Agua}

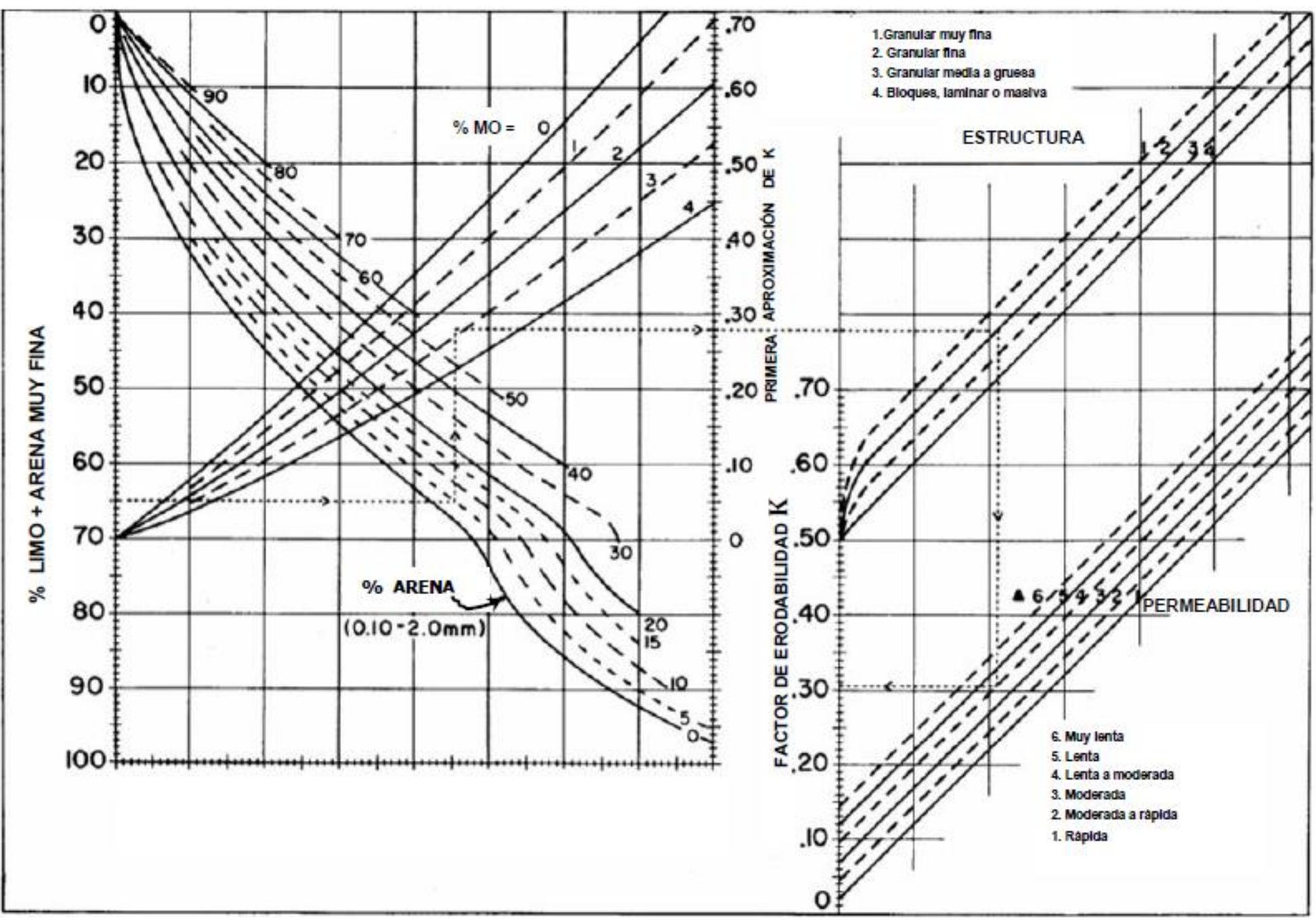

Figura 2. Nomograma para la determinación de la erosionabilidad del suelo (adaptado por Wischmeier y Smith, 1978).

La densidad aparente, conductividad hidráulica y capacidad de agua disponible en la capa del suelo se obtuvieron con ayuda del software Soil Water Characteristics Program (SPAW, por sus siglas en inglés), el cual requiere como datos de entrada los contenidos de arena, arcilla y materia orgánica. 


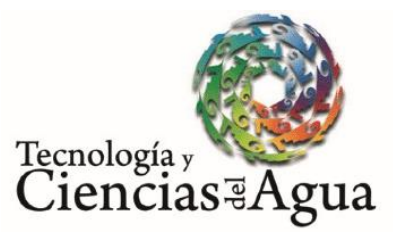

2021, Instituto Mexicano de Tecnología del Agua

Open Access bajo la licencia CC BY-NC-SA 4.0

(https://creativecommons.org/licenses/by-nc-sa/4.0/)

\section{Clima}

El modelo SWAT necesita datos diarios de precipitación y temperatura (máxima y mínima), como información mínima, con los cuales su generador de clima WXGEN simula la humedad relativa, radiación solar y velocidad del viento. Los datos diarios del clima se obtuvieron de la estación meteorológica Chapingo y fueron los correspondientes a los periodos 1964-1970, 1971-1975 y 1997-2014 (usados para calibrar, validar y analizar el impacto del cambio de uso de suelo sobre el escurrimiento superficial, respectivamente), e ingresados a SWAT a nivel diario mediante el formato de archivo de texto.

Además de obtener los datos diarios de precipitación y temperatura para el periodo 1964-2015, se procesaron los datos diarios de precipitación del periodo 1955-2015 para obtener la precipitación media mensual (PCPMM), desviación estándar de la precipitación media (PCPSTD), coeficiente de sesgo (PCPSKW), probabilidad de un día húmedo después de un día seco (PR_W1), probabilidad de un día húmedo después de un día húmedo (PR_W2); así como los datos de 1955 a 2015 correspondientes a temperatura (máxima y mínima), promedio de temperatura máxima (TMPMX), promedio de temperatura mínima (TMPMN), desviación estándar de la temperatura máxima diaria en el mes (TMPSTDMX) y la desviación estándar de la temperatura mínima en el mes (TMPSTDMN). 


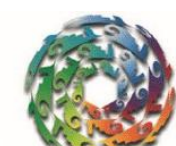

Ciencias $\asymp$ Agua
2021, Instituto Mexicano de Tecnología del Agua

Open Access bajo la licencia CC BY-NC-SA 4.0

(https://creativecommons.org/licenses/by-nc-sa/4.0/)

Otro dato requerido para la información climatológica es la precipitación máxima cada 30 minutos del registro mensual, para ello se aplicó el método de Chen (1983), ya que arroja buenos resultados para estimar la intensidad de lluvia máxima mensual (Ramírez, López, \& Ibáñez, 2015). Dicho método parte de la siguiente ecuación:

$P_{t}^{T}=\frac{a P_{1}^{10} \log \left(10^{2-x} T^{x-1}\right)}{t+b^{c}} *\left(\frac{t}{60}\right)$

Donde $P_{t}^{T}$ es la altura de precipitación en mm para un periodo $T$ en años y una lluvia de $t$ minutos; $a, b$ y $c$ son parámetros que dependen del cociente de lluvia-duración $R$ :

$R=\frac{P_{1}^{2}}{P_{24}^{2}}$

Donde $R$ es el cociente lluvia-duración; $P_{1}^{2}$ la lluvia de una hora y periodo de retorno de dos años, y $P_{24}^{2}$ es la lluvia de $24 \mathrm{~h}$ para el mismo periodo de retorno.

Las variables $a, b$ y $c$ se calculan con las ecuaciones siguientes:

$$
\begin{aligned}
& a=-2.297536+100.0389 R-432.5438 R^{2}+1256.228 R^{3}-1028.902 R^{4} \\
& b=-9.845761+96.94864 R-341.4349 R^{2}+757.9172 R^{3}-598.7461 R^{4}
\end{aligned}
$$


$c=-0.06498345+5.069294 R-16.08111 R^{2}+29.09596 R^{3}-20.06288 R^{4}$

\section{Manejo}

En este estudio los datos de manejo para la zona agrícola se obtuvieron de Licona-Santana, Martínez-Menes, Mendoza-Onofre, Figueroa-Sandoval y Fernández-Reynoso (2006).

\section{Calibración y validación del modelo}

La calibración y validación del modelo se realizó mediante el uso del software SWAT-CUP, utilizando el registro de los gastos observados de 1964 a 1970. En la calibración se utilizaron los datos de 1964 y 1965, como calentamiento para obtener un ajuste satisfactorio entre los gastos observados y los simulados, mediante el cambio de los valores de los parámetros más sensibles, como lo indican Zhang et al. (2017). La validación se hizo con los gastos del periodo 1966-1970.

Con el procedimiento SUFI-2 del SWAT-CUP se optimizaron los parámetros más sensibles del modelo. En las 2000 simulaciones se utilizó el coeficiente de Nash-Sutcliffe (NSE) como estimador de la eficiencia del 
modelo, pues cuantifica el ajuste entre los valores observados y simulados. Asimismo, se usó el $R^{2}$ como una prueba de bondad de ajuste entre los resultados simulados y observados.

Una vez calibrado el modelo, se hizo la validación para el periodo 1971-1975. Finalmente, se aplicó el modelo para el periodo 1999-2015, con el fin de simular el efecto del cambio de uso de suelo sobre el escurrimiento superficial. Para esto se introdujo el porcentaje de cambio de uso de suelo obtenido de la imagen RapidEye del 22 de marzo de 2011.

\section{Resultados y discusión}

\section{Cambios en el uso de suelo y vegetación}

Se definieron nueve categorías generales para la interpretación de los usos del suelo de la cuenca de estudio a partir de la información reportada por INEGI (Serie II y VI) y del recorrido de campo. En la Figura 3 y Figura 4 se muestran los mapas de clasificación de uso de suelo y vegetación de 
la cuenca del río Chapingo, correspondiente a los años 1999 y 2011, respectivamente.

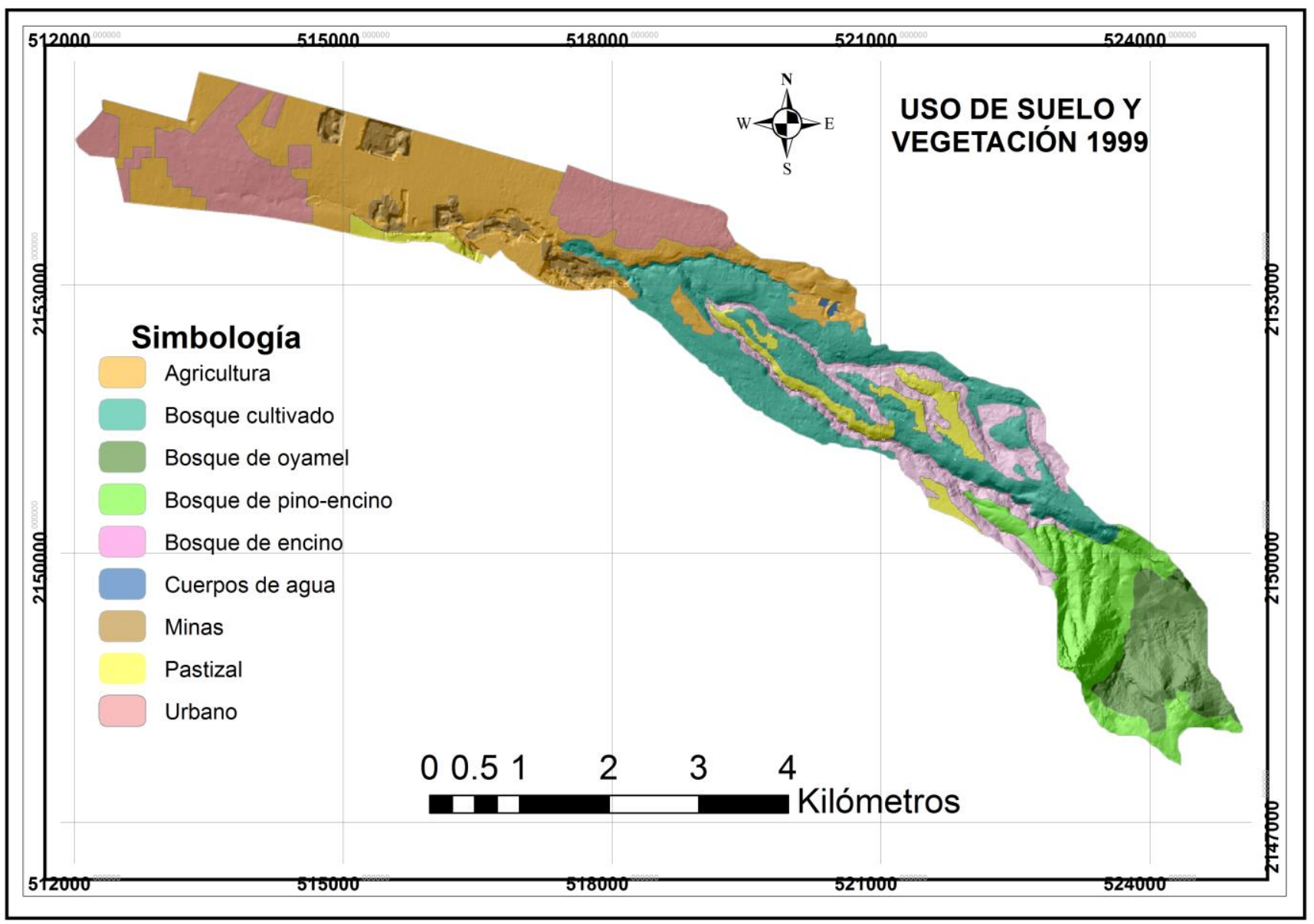

Figura 3. Mapa de uso de suelo y vegetación 1999 de la cuenca del Río Chapino mediante una imagen Landsat, información de INEGI y recorrido de campo. 
Ciencias $₫$ Agua

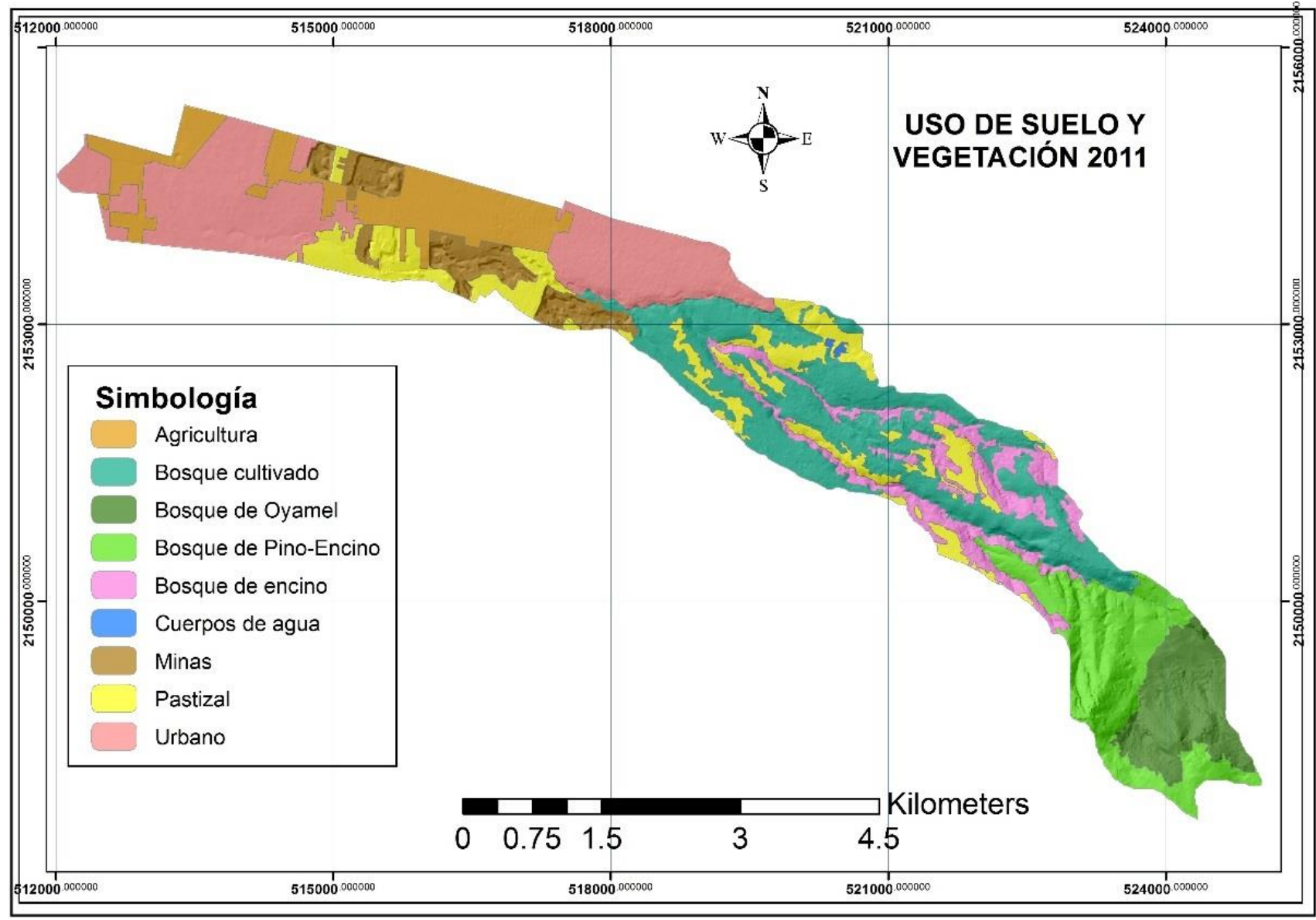

Figura 4. Mapa de usos de suelo y vegetación 2011 de la cuenca del Río Chapingo mediante una imagen RapidEye, información de INEGI y recorrido de campo.

La comparación de las figuras antes mencionadas indica que en el periodo 1999-2011 el área agrícola se redujo debido al crecimiento de la zona urbana y el área de minería; de igual forma, se redujo la superficie ocupada por bosques de oyamel y encino. El otro uso de suelo que aumentó fue el pastizal. El incremento de la zona de minas se puede relacionar con el aumento de la zona urbana en la cuenca y con el 
desarrollo inmobiliario en la zona metropolitana de la Ciudad de México. Esta tendencia pudo subir en el último lustro (periodo no evaluado) con la construcción del Nuevo Aeropuerto de la Ciudad de México, que estuvo demandando cantidades extraordinarias de materiales pétreos, en su mayor parte provenientes de la cuenca del río Chapingo.

Los cambios de mayor magnitud ocurrieron en los usos de agricultura, pastizal, área de minas y zona urbana. El área de agricultura disminuyó en 293.44 ha; la mancha urbana se incrementó en 117.33 ha, y tanto la zona de pastizales como la de minas se duplicaron.

Las tasas de cambio anual promedio en el periodo de estudio de la superficie dedicada a la agricultura, pastizal, minería y zona urbana fueron $-6.9,7.75,5.04$ y $2.89 \%$, respectivamente (Tabla 2 ).

Tabla 2. Usos de suelo y vegetación para los años 1999 y 2011 de la cuenca del río Chapingo.

\begin{tabular}{|c|c|c|c|c|}
\hline \multirow[b]{2}{*}{ Categoría } & \multicolumn{2}{|c|}{ Superficie (ha) } & \multirow{2}{*}{$\begin{array}{c}\text { Cambio de } \\
1999 \text { a } \\
2011 \text { (ha) }\end{array}$} & \multirow{2}{*}{$\begin{array}{l}\text { Cambio anual } \\
\text { promedio (\%) }\end{array}$} \\
\hline & 1999 & 2011 & & \\
\hline Agricultura & 509.33 & 215.89 & -293.44 & -6.90 \\
\hline Bosque cultivado & 397.39 & 412.91 & 15.52 & 0.32 \\
\hline Bosque de oyamel & 156.24 & 144.44 & -11.80 & -0.65 \\
\hline Bosque de pino-encino & 218.69 & 232.43 & 13.74 & 0.51 \\
\hline Bosque de encino & 190.37 & 156.44 & -33.93 & -1.62 \\
\hline Pastizal & 96.54 & 236.46 & 139.92 & 7.75 \\
\hline Minas & 65.13 & 117.51 & 52.38 & 5.04 \\
\hline Cuerpos de agua & 1.95 & 2.23 & 0.28 & 1.12 \\
\hline
\end{tabular}




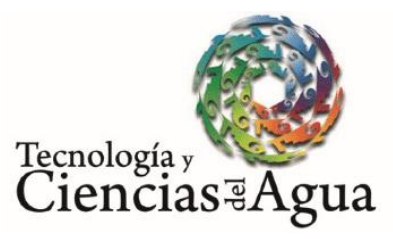

Urbano

Total
287.78

1923.42
2021, Instituto Mexicano de Tecnología del Agua

Open Access bajo la licencia CC BY-NC-SA 4.0

(https://creativecommons.org/licenses/by-nc-sa/4.0/)

La tasa de cambio anual de la zona urbana de la cuenca del río Chapingo (2.89 \%) es mayor a la del Estado de México (1.6 \%) para el periodo 1997-2009 (Camacho-Sanabria et al., 2015). Este resultado del presente estudio -en virtud de que la cuenca bajo estudio geográficamente está próxima a la Ciudad de México- es coherente con Moreno-Sánchez (2013), quien reporta que para el periodo 2000-2010 el patrón de asentamientos humanos del Estado de México se relacionó con la expansión física de la Ciudad de México y su zona conurbada, donde el crecimiento demográfico es variable, y se asocia con la migración de personas y familias que buscan mejores oportunidades de vida y empleo.

Los resultados del presente estudio contrastan con lo encontrado por Camacho-Sanabria et al. (2015), y García, Gutiérrez y Balderas (2011), quienes reportan un incremento en la superficie agrícola del Estado de México debido a la deforestación de los bosques.

En la presente investigación, la disminución de la zona agrícola se atribuye al crecimiento poblacional, pues en el periodo 2000-2010, en el municipio de Texcoco, el número de habitantes pasó de 204102 a 235 151 (censo poblacional) (INEGI, 2000; INEGI, 2010); asimismo, el INEGI (2010) indica que el $1.4 \%$ de la población proviene de otros estados, principalmente del sur y centro del país, y se ha asentado en las comunidades donde el uso de suelo y la prestación de servicios son más baratos. 
En otros lugares también se ha reportado la disminución del área, por ejemplo, López et al. (2015) indican que la agricultura de temporal bajó 28 \% en la zona Mazahua del altiplano mexicano de 2000-2010, y Gordillo-Ruiz y Castillo-Santiago (2017) reportan que el área de cultivada decreció en 3538 ha en la cuenca del río Sabinal, Chiapas, para el periodo 1992-2009 debido al incremento de la zona urbana.

\section{Relación de NDVI con los cambios de uso de suelo}

Los valores de NDVI de cada uno de los usos de suelo aumentaron en una magnitud absoluta, al comparar el primer y último año del periodo 19992011 (Tabla 3), lo cual se puede deber a la mayor precipitación registrada al final $(684 \mathrm{~mm})$ respecto del inicio $(530 \mathrm{~mm})$ de dicho periodo. Los registros de precipitación se usaron como parte de los insumos del modelo. La diferencia entre los promedios de NDVI también se puede atribuir al tipo de imágenes que se compararon, ya que la banda red edge, que contiene la imagen de 2011, es mejor que la banda infrarrojo cercano, que posee la imagen de 1999. 
Tabla 3. Valores de NDVI para los usos de suelo de 1999 y 2011 de la cuenca del río Chapingo.

\begin{tabular}{|c|c|c|c|c|c|c|c|c|c|}
\hline \multirow[b]{3}{*}{ Usos de suelo } & \multicolumn{8}{|c|}{ Valores de NDVI } & \multirow[b]{3}{*}{$\begin{array}{c}\text { Diferenci } \\
\text { a de la } \\
\text { media }\end{array}$} \\
\hline & \multicolumn{3}{|c|}{1999} & \multicolumn{5}{|c|}{2011} & \\
\hline & $\begin{array}{c}\text { Mínim } \\
\text { o }\end{array}$ & $\begin{array}{c}\text { Máxim } \\
\text { o }\end{array}$ & $\begin{array}{c}\text { Medi } \\
\quad a\end{array}$ & DE* & $\begin{array}{c}\text { Mínim } \\
\text { o }\end{array}$ & $\begin{array}{c}\text { Máxim } \\
\text { o }\end{array}$ & $\begin{array}{c}\text { Medi } \\
\quad \text { a }\end{array}$ & DE* & \\
\hline \multirow[t]{2}{*}{ Agricultura } & -0.516 & 0.824 & - & 0.12 & -0.312 & 0.627 & - & 0.12 & 0.130 \\
\hline & & & 0.149 & 9 & & & 0.019 & 0 & \\
\hline \multirow[t]{2}{*}{ Bosque cultivado } & -0.276 & 0.398 & - & 0.08 & -0.311 & 0.456 & 0.065 & 0.08 & 0.152 \\
\hline & & & 0.087 & 1 & & & & 3 & \\
\hline \multirow[t]{2}{*}{ Bosque de oyamel } & -0.084 & 0.514 & 0.248 & 0.09 & 0.014 & 0.560 & 0.353 & 0.07 & 0.105 \\
\hline & & & & 1 & & & & 0 & \\
\hline Bosque de pino- & -0.165 & 0.537 & 0.163 & 0.11 & -0.050 & 0.561 & 0.258 & 0.09 & 0.096 \\
\hline encino & & & & 9 & & & & 1 & \\
\hline \multirow[t]{2}{*}{ Bosque de encino } & -0.215 & 0.340 & 0.029 & 0.09 & -0.125 & 0.527 & 0.156 & 0.09 & 0.126 \\
\hline & & & & 6 & & & & 6 & \\
\hline \multirow[t]{2}{*}{ Pastizal } & -0.349 & 0.293 & - & 0.06 & -0.440 & 0.476 & - & 0.06 & 0.114 \\
\hline & & & 0.138 & 7 & & & 0.024 & 2 & \\
\hline \multirow[t]{2}{*}{ Minas } & -0.396 & -0.053 & - & 0.03 & -0.246 & 0.398 & - & 0.04 & 0.185 \\
\hline & & & 0.266 & 9 & & & 0.081 & 7 & \\
\hline \multirow[t]{2}{*}{ Cuerpos de agua } & -0.487 & -0.096 & - & 0.10 & -0.439 & 0.414 & - & 0.16 & 0.161 \\
\hline & & & 0.257 & 5 & & & 0.097 & 7 & \\
\hline \multirow[t]{2}{*}{ Urbano } & -0.356 & 0.422 & - & 0.06 & -0.356 & 0.542 & - & 0.08 & 0.124 \\
\hline & & & 0.152 & 7 & & & 0.028 & 2 & \\
\hline
\end{tabular}

*DE: desviación estándar.

Los valores de NDVI más altos para este estudio corresponden a las zonas forestales y valores bajos para las áreas de minas, cuerpos de agua y zona urbana debido a que disminuye la cobertura vegetal y, por tanto, la reflectancia es baja. Ello está de acuerdo con Meneses-Tovar (2011), quien menciona que, en la práctica, los valores que están por debajo de 
0.1 corresponden a los cuerpos de agua y a la tierra desnuda, mientras que los valores más altos de NDVI son indicadores de la actividad fotosintética de las zonas de matorral, bosque templado, selva y actividad agrícola.

Sin embargo, los valores medios de NDVI no coinciden con los reportados por Márquez (2013), quien en su estudio obtuvo valores de NDVI mayores en todos los casos de uso suelo para la misma zona de estudio. Una explicación a esto es que él utilizó imágenes del mes de septiembre y octubre, y para este estudio fueron del mes de marzo, cuando la temporada de lluvias aún no empieza, y las zonas agrícolas en general tienen vegetación escasa, comparada con las áreas de bosques y pastizales. Al respecto, Díaz (2015) menciona que cuando la vegetación sufre algún tipo de estrés, ya sea por presencia de plagas o por sequía, la cantidad de agua disminuye en las paredes celulares y, por lo tanto, la reflectividad disminuye en el infrarrojo cercano y aumenta paralelamente en el rojo, al tener menor cantidad de clorofila asociada con menor verdor, obteniéndose valores de NDVI menores.

\section{Modelación hidrológica con SWAT}


Entre las opciones de simulación (diaria, mensual y anual) del SWAT se eligió la mensual, pues facilita el análisis de datos de salida debido a la cantidad de datos generados y manejados.

La aplicación del SWAT a la cuenca bajo estudio generó 13 subcuencas, y el reporte global, el cual incluye información sobre la cuenca, subcuencas, área, suelos, coberturas vegetales, pendientes y el número de HRU's, que en este caso fue 279.

\section{Calibración del modelo SWAT}

El análisis de sensibilidad mostró los parámetros con mayor grado de sensibilidad (Tabla 4), que como parte de la metodología fueron modificados para generar la mejor correlación entre los caudales simulado y observado del periodo 1966-1970.

Tabla 4. Parámetros más sensibles que afectan al modelo SWAT para el periodo 1966-1970.

\begin{tabular}{lcccc}
\hline $\begin{array}{c}\text { Parámetro a } \\
\text { modificar }\end{array}$ & Significado & $\begin{array}{c}\text { Grado de } \\
\text { sensibilidad }\end{array}$ & $\begin{array}{c}\text { Parámetro de salida } \\
\text { que modifica }\end{array}$ & $\begin{array}{c}\text { Archivo } \\
\text { de } \\
\text { entrada }\end{array}$
\end{tabular}




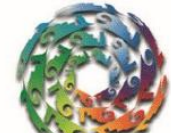

Ciencias $\approx$ Agua

\begin{tabular}{|c|c|c|c|c|}
\hline $\mathrm{CN} 2$ & Curva numérica & Alto & $\begin{array}{l}\text { Escurrimiento } \\
\text { superficial }\end{array}$ &. $\mathrm{mgt}$ \\
\hline ALPHA_BF & Factor alfa del flujo base & Medio & $\begin{array}{l}\text { Escurrimiento } \\
\text { subsuperficial }\end{array}$ &.$g w$ \\
\hline REVAPMN & $\begin{array}{l}\text { Umbral de profundidad del } \\
\text { agua en el acuífero superficial }\end{array}$ & Alto & $\begin{array}{c}\text { Evaporación } \\
\text { Escurrimiento de } \\
\text { retorno }\end{array}$ &.$g w$ \\
\hline GWQMN & $\begin{array}{l}\text { Profundidad del umbral de } \\
\text { agua en el acuífero superficial }\end{array}$ & Alto & $\begin{array}{c}\text { Evaporación } \\
\text { Escurrimiento de } \\
\text { retorno }\end{array}$ &.$g w$ \\
\hline GW_REVAP & $\begin{array}{l}\text { Coeficiente de agua } \\
\text { subterránea }\end{array}$ & Alto & $\begin{array}{c}\text { Evaporación } \\
\text { Escurrimiento de } \\
\text { retorno }\end{array}$ &.$g w$ \\
\hline GW_DELAY & $\begin{array}{l}\text { Temporizador de retardo } \\
\text { subterráneo }\end{array}$ & Medio & $\begin{array}{l}\text { Escurrimiento } \\
\text { superficial }\end{array}$ &.$g w$ \\
\hline ESCO & $\begin{array}{l}\text { Factor de compensación de la } \\
\text { evaporación en el suelo }\end{array}$ & Medio & Evaporación & .bsn \\
\hline SOL_AWC & $\begin{array}{l}\text { Capacidad de agua disponible } \\
\text { en el suelo }\end{array}$ & Alto & $\begin{array}{l}\text { Escurrimiento } \\
\text { superficial }\end{array}$ & sol \\
\hline SLSUBBSN & Longitud de la pendiente & Medio & $\begin{array}{l}\text { Escurrimiento de } \\
\text { retorno }\end{array}$ & .hru \\
\hline
\end{tabular}

La calibración del modelo tuvo un ajuste de bondad satisfactorio $($ NSE $=0.58)$, de acuerdo con la clasificación de desempeño propuesto por Fernández, Acuña, Díaz y Felipe (2016) para el modelo SWAT. En la Figura 5 se presentan los gastos observados y los datos calibrados. En la Figura 6 se muestra el resultado del análisis de regresión entre dichos gastos. 
2021, Instituto Mexicano de Tecnología del Agua

Open Access bajo la licencia CC BY-NC-SA 4.0

Tecnología y

(https://creativecommons.org/licenses/by-nc-sa/4.0/)

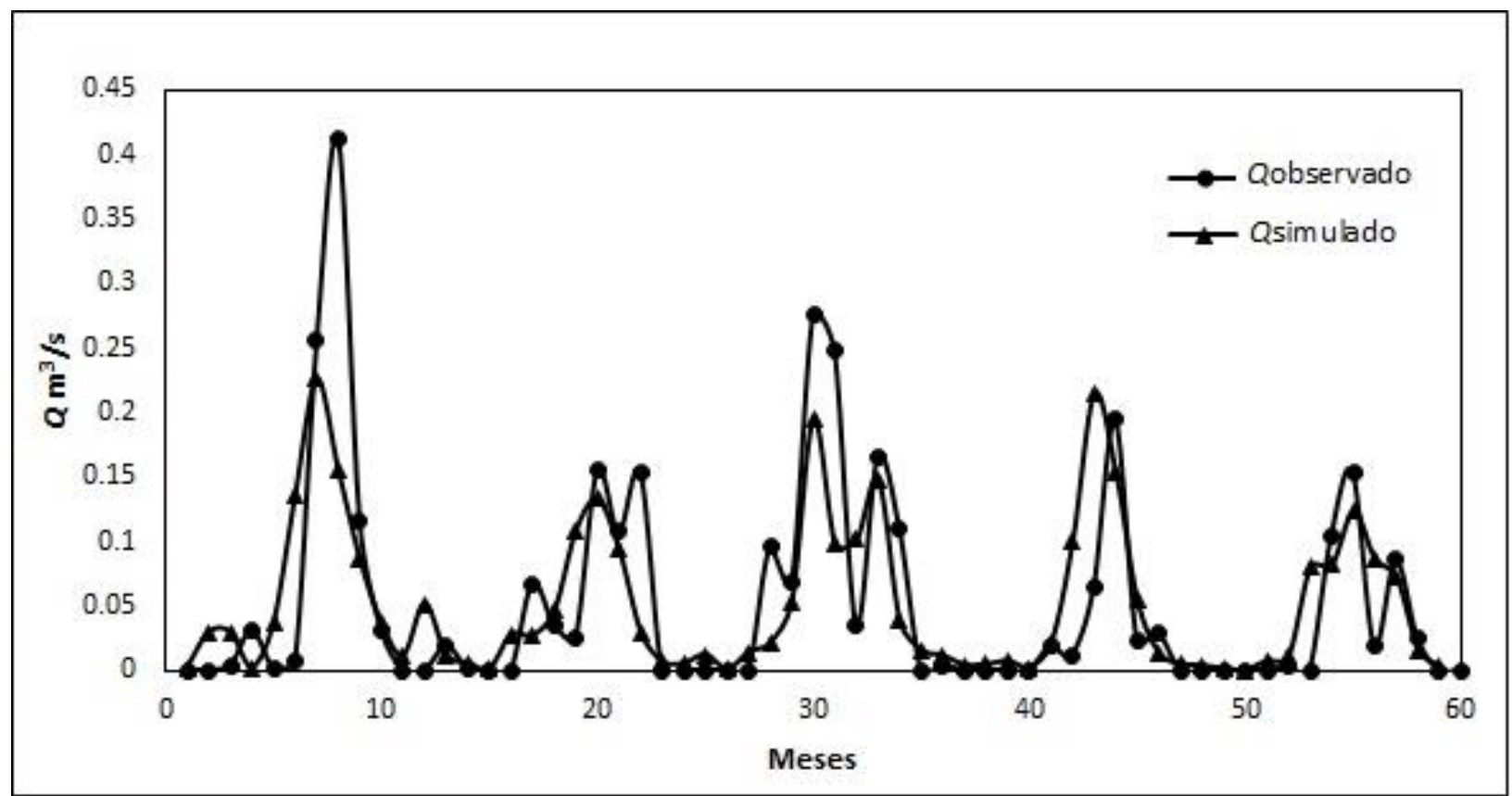

Figura 5. Gastos observados y calibrados para el periodo 1966-1970. 


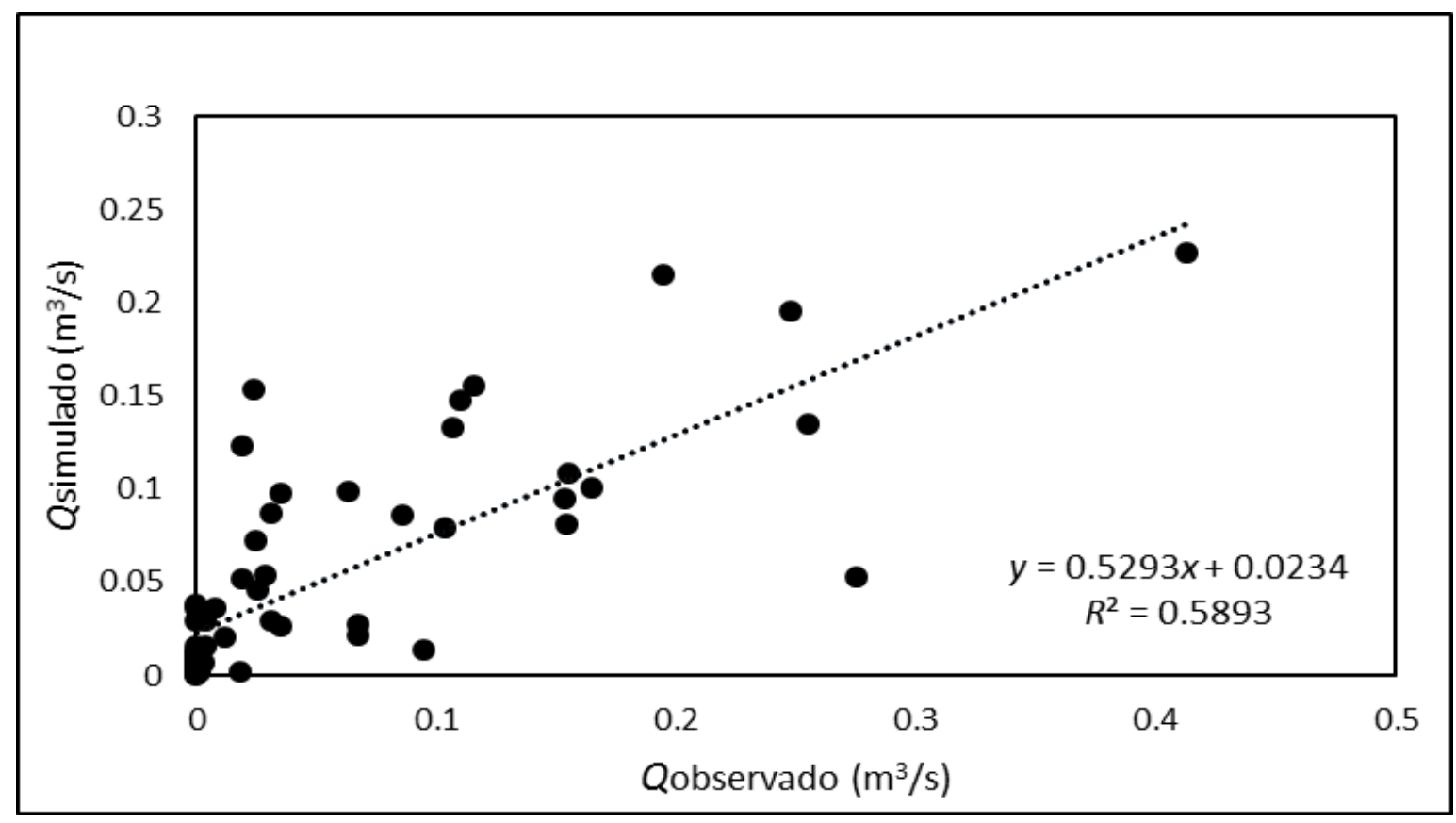

Figura 6. Análisis de regresión de los datos observados y calibrados para el periodo 1966-1970.

Los resultados obtenidos en la calibración del presente estudio comparados con otros en los que también se utilizó el SWAT y se obtuvieron mejores ajustes puede deberse a que se tuvo que recurrir al uso de diversos supuestos ante la escasez de información que requiere el modelo. Vargas-Castañeda et al. (2015) advierten que una de las limitaciones del modelo SWAT en México es la gran cantidad de datos que necesita, la cual no siempre está disponible en las bases de datos que las instituciones gubernamentales tienen de manera cotidiana.

Una vez calibrado el modelo, su validación para el periodo 19711975 consistió en medir su capacidad predictiva mediante la comparación de los gastos observados y los simulados con los parámetros 
determinados en su calibración. En la Figura 7 se presenta el análisis de regresión del periodo validado. Dicha validación generó una bondad de ajuste satisfactoria (NSE $=0.52$ ).

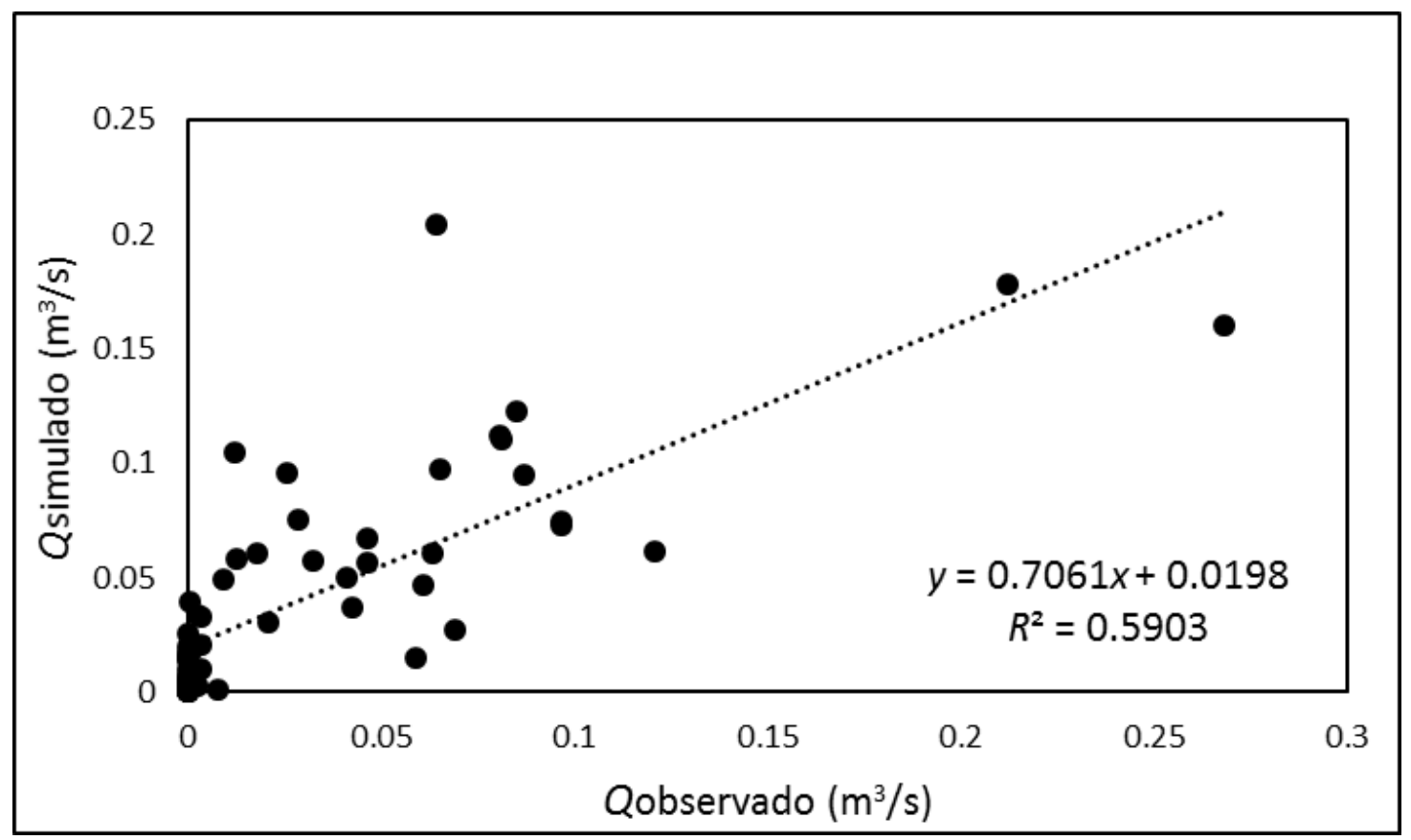

Figura 7. Análisis de regresión para el periodo 1971-1975.

\section{Efecto del cambio de uso de suelo en el escurrimiento superficial y salida de sedimentos}

El modelo calibrado y validado se aplicó al periodo 1999-2015 para analizar la influencia del cambio de uso de suelo sobre el escurrimiento 
superficial, mediante el análisis previo de dos mapas de uso de suelo, uno de 1999 y el otro de 2011. Los escurrimientos mensuales simulados para este periodo a partir de los dos mapas antes indicado se muestran en la Figura 8.

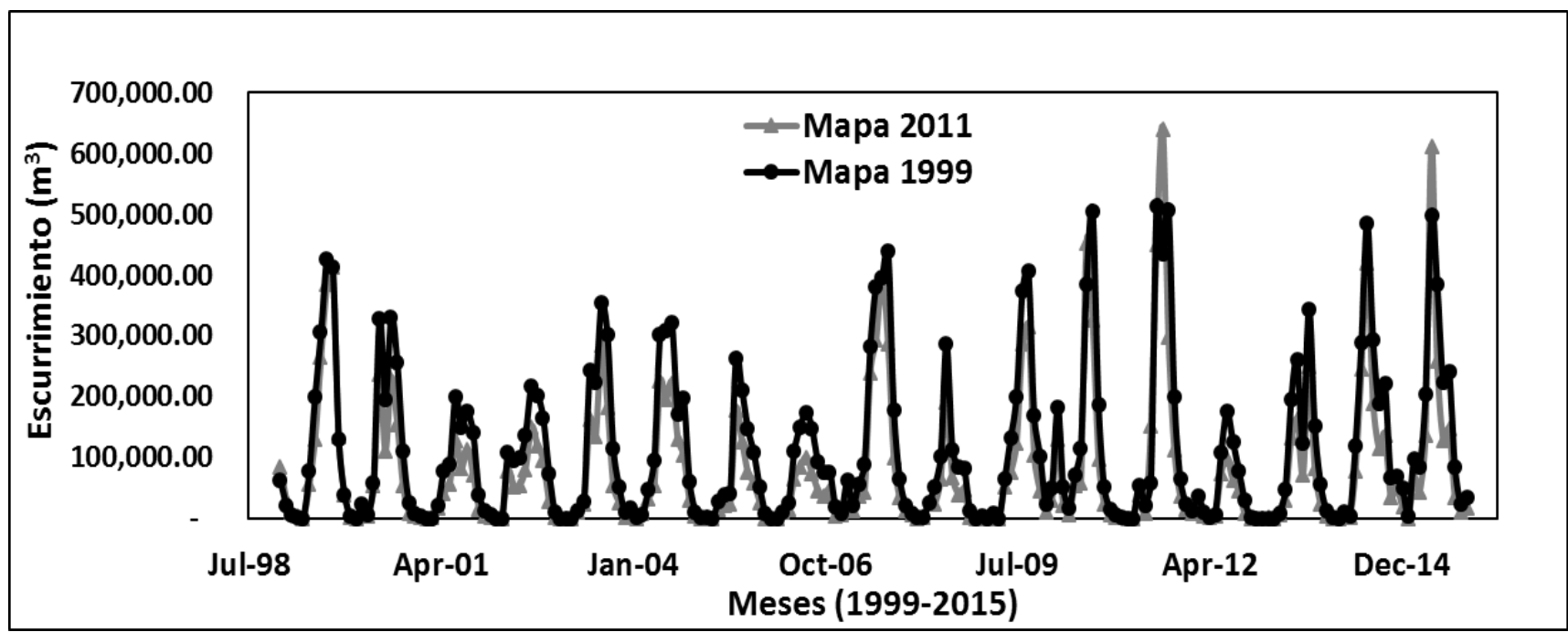

Figura 8. Escurrimientos mensuales simulados para el periodo 19992015, a partir de dos mapas de uso de suelo.

Los resultados de este estudio indican que el cambio de uso de suelo no modificó la magnitud del escurrimiento superficial. Esto se puede deber a que los cambios de uso de suelo durante el periodo evaluado por ser pequeños no fueron suficientes para modificar de forma significativa el volumen de escurrimiento, así como al tamaño pequeño de las subcuencas, como lo mencionan Trucios, Martínez, Blando y Sánchez (2007), quienes en su estudio de calibración y validación del modelo SWAT para dos coberturas de suelo confirmaron, al comparar tres tamaños diferentes de subcuencas, que el modelo es sensible a este 


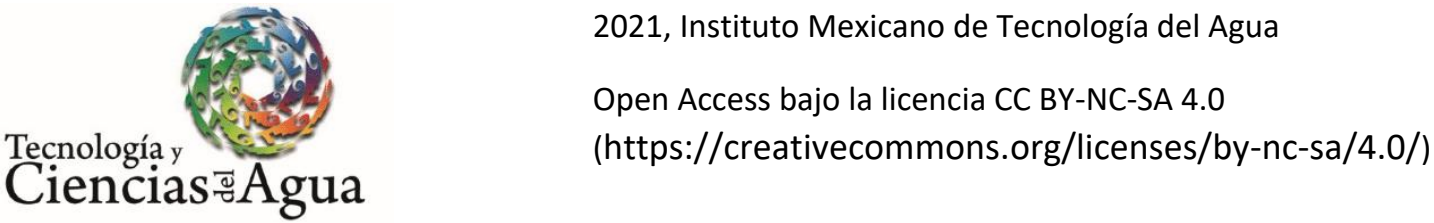

factor, porque se basa principalmente en el uso de suelo y vegetación predominante en la subcuenca para calcular las variables de salida.

En la Tabla 5 se presentan los escurrimientos mensual y anual simulados del periodo de 1999-2015. Estos datos muestran que 2007 y 2011 son los años con mayor escurrimiento; asimismo en julio, agosto y septiembre ocurre mayor escurrimiento en ambos años. Esto se atribuye a la precipitación mayor ocurrida dentro del periodo de lluvias más abundantes (junio a septiembre).

Tabla 5. Escurrimientos mensuales y anuales simulados por el modelo SWAT para el periodo 1999-2015 de la cuenca del río Chapingo.

Escurrimiento superficial (miles de $\mathbf{m}^{3}$ )

\begin{tabular}{cccccccccccccc} 
Año & Ene. & Feb. & Mar. & Abr. & May. & Junio & Julio & Ago. & Sep. & Oct. & Nov. & Dic. & Anual \\
\hline 1999 & 62.78 & 21.90 & 6.83 & 2.67 & 0.34 & 77.24 & 199.51 & 306.14 & 427.16 & 412.74 & 131.21 & 39.24 & 1687.76 \\
2000 & 3.90 & 0.00 & 24.04 & 6.11 & 58.74 & 328.15 & 196.14 & 330.25 & 256.84 & 110.24 & 26.31 & 9.15 & 1349.87 \\
2001 & 4.45 & 0.09 & 0.63 & 21.19 & 76.98 & 88.93 & 200.91 & 149.05 & 175.48 & 140.54 & 39.27 & 12.25 & 909.76 \\
2002 & 6.08 & 0.47 & 0.00 & 109.28 & 96.45 & 99.17 & 137.29 & 218.34 & 203.14 & 165.15 & 74.21 & 10.25 & 1119.83 \\
2003 & 0.46 & 0.00 & 0.00 & 13.55 & 26.86 & 243.34 & 222.90 & 354.08 & 301.45 & 115.55 & 51.37 & 9.94 & 1339.49 \\
2004 & 16.03 & 0.85 & 5.78 & 46.47 & 95.78 & 301.97 & 308.02 & 321.41 & 171.33 & 198.39 & 61.09 & 11.40 & 1538.53 \\
2005 & 2.66 & 1.27 & 0.36 & 27.06 & 38.76 & 41.39 & 263.23 & 210.92 & 147.12 & 108.72 & 52.67 & 7.63 & 901.80 \\
2006 & 0.14 & 0.00 & 11.23 & 26.18 & 110.91 & 150.15 & 174.18 & 147.58 & 93.13 & 76.41 & 76.75 & 19.68 & 886.35 \\
2007 & 8.45 & 61.76 & 21.93 & 55.52 & 88.68 & 283.05 & 380.33 & 396.67 & 440.38 & 178.09 & 65.16 & 21.62 & 2001.65 \\
2008 & 9.37 & 1.44 & 0.80 & 25.10 & 52.84 & 100.93 & 286.05 & 113.43 & 84.19 & 82.76 & 11.82 & 0.11 & 768.85 \\
2009 & 3.93 & 0.00 & 8.09 & 0.00 & 65.46 & 132.58 & 200.32 & 373.37 & 406.17 & 168.44 & 103.01 & 23.25 & 1484.61 \\
2010 & 49.98 & 183.40 & 52.18 & 17.51 & 70.42 & 115.34 & 384.35 & 505.68 & 187.17 & 50.84 & 14.01 & 5.48 & 1636.35 \\
2011 & 1.24 & 0.00 & 0.67 & 39.92 & 7.60 & 152.62 & 451.31 & 640.67 & 297.04 & 111.98 & 36.16 & 15.80 & 1755.01
\end{tabular}


Tecnología y

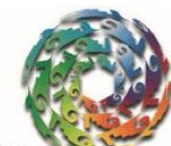

Ciencias $\approx$ Agua
2021, Instituto Mexicano de Tecnología del Agua

Open Access bajo la licencia CC BY-NC-SA 4.0

(https://creativecommons.org/licenses/by-nc-sa/4.0/)

$\begin{array}{rrrrrrrrrrrrrr}2012 & 9.17 & 23.29 & 4.92 & 1.07 & 4.74 & 74.13 & 98.19 & 62.49 & 44.66 & 7.57 & 0.53 & 0.00 & 330.77 \\ 2013 & 0.00 & 0.78 & 0.00 & 6.14 & 29.52 & 133.20 & 161.99 & 70.63 & 250.98 & 82.47 & 23.03 & 2.92 & 761.66 \\ 2014 & 0.46 & 0.01 & 6.48 & 2.41 & 77.81 & 245.02 & 419.17 & 190.06 & 114.90 & 137.88 & 34.34 & 52.20 & 1280.75 \\ 2015 & 18.46 & 0.54 & 65.86 & 44.27 & 136.12 & 611.71 & 257.80 & 129.18 & 146.99 & 35.49 & 10.87 & 17.70 & 1474.99\end{array}$

En la Tabla 6 se presenta la producción de sedimentos simulados. Es importante indicar que el SWAT no fue calibrado debido a la inexistencia de datos de campo; por lo tanto, para esta variable no pudo conocerse la capacidad predictiva de dicho modelo. Asimismo, es oportuno indicar que algunos autores mencionan que el modelo SWAT tiene mayor capacidad predictiva para la producción de escurrimientos que de sedimentos (Torres-Benitez, Fernández-Reynoso, Oropeza-Mota, \& Mejía-Saenz, 2004; Salas-Martínez et al., 2014; Sánchez-Galindo, Fernández-ReynosoMartínez-Menes, Rubio-Granados, \& Ríos-Berber, 2017).

Tabla 6. Producción de sedimentos de la cuenca del río Chapingo simulados por el modelo SWAT para el periodo de 1999-2015.

\section{Producción de sedimentos (toneladas)}

Año Ene. Feb. Mar. Abr. May. Jun. Jul. Ago. Sep. Oct. Nov. Dic. Anual

\begin{tabular}{llllllllllllll}
\hline 1999 & 0.00 & 0.06 & 0.02 & 0.02 & 0.00 & 1.76 & 5.80 & 1.72 & 0.44 & 0.63 & 0.09 & 0.11 & 10.63 \\
2000 & 0.00 & 0.00 & 0.38 & 0.05 & 1.63 & 6.50 & 0.58 & 1.45 & 0.62 & 0.17 & 0.00 & 0.02 & 11.41 \\
2001 & 0.02 & 0.00 & 0.01 & 0.34 & 1.45 & 0.57 & 0.88 & 0.49 & 0.68 & 0.27 & 0.09 & 0.07 & 4.87 \\
2002 & 0.01 & 0.00 & 0.00 & 2.81 & 0.97 & 0.49 & 0.63 & 1.02 & 0.60 & 0.64 & 0.05 & 0.00 & 7.22 \\
2003 & 0.00 & 0.00 & 0.00 & 0.19 & 0.50 & 4.02 & 0.90 & 1.20 & 0.71 & 0.06 & 0.13 & 0.00 & 7.71 \\
2004 & 0.15 & 0.00 & 0.10 & 1.00 & 2.04 & 3.25 & 0.96 & 0.73 & 0.82 & 0.29 & 0.10 & 0.00 & 9.45
\end{tabular}


Tecnología y

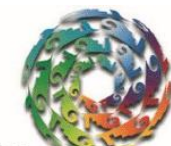

Ciencias $\approx$ Agua
2021, Instituto Mexicano de Tecnología del Agua

Open Access bajo la licencia CC BY-NC-SA 4.0

(https://creativecommons.org/licenses/by-nc-sa/4.0/)

\begin{tabular}{llllllllllllll}
2005 & 0.00 & 0.01 & 0.00 & 0.29 & 0.49 & 0.28 & 1.28 & 0.75 & 0.24 & 0.39 & 0.21 & 0.00 & 3.93 \\
2006 & 0.00 & 0.00 & 0.18 & 0.37 & 2.43 & 0.51 & 0.61 & 0.43 & 0.33 & 0.20 & 0.36 & 0.00 & 5.40 \\
2007 & 0.09 & 0.21 & 0.19 & 0.35 & 0.30 & 1.55 & 1.18 & 1.46 & 0.78 & 0.30 & 0.04 & 0.00 & 6.44 \\
2008 & 0.00 & 0.00 & 0.00 & 0.29 & 0.20 & 0.62 & 0.95 & 0.47 & 0.20 & 0.37 & 0.00 & 0.00 & 3.09 \\
2009 & 0.00 & 0.00 & 0.09 & 0.00 & 0.60 & 0.59 & 0.78 & 1.59 & 0.88 & 0.57 & 0.00 & 0.04 & 5.15 \\
2010 & 0.17 & 1.24 & 0.19 & 0.09 & 0.68 & 0.41 & 1.91 & 0.83 & 0.22 & 0.00 & 0.00 & 0.00 & 5.74 \\
2011 & 0.00 & 0.00 & 0.00 & 0.58 & 0.05 & 1.78 & 2.07 & 1.60 & 0.61 & 0.45 & 0.05 & 0.00 & 7.18 \\
2012 & 0.00 & 0.23 & 0.06 & 0.01 & 0.09 & 0.90 & 0.79 & 0.54 & 0.56 & 0.00 & 0.00 & 0.00 & 3.16 \\
2013 & 0.00 & 0.00 & 0.00 & 0.13 & 0.47 & 1.45 & 1.01 & 0.73 & 1.77 & 0.57 & 0.06 & 0.00 & 6.20 \\
2014 & 0.00 & 0.00 & 0.13 & 0.02 & 1.01 & 1.75 & 1.52 & 0.98 & 0.80 & 0.79 & 0.16 & 0.42 & 7.58 \\
2015 & 0.00 & 0.00 & 0.52 & 0.43 & 1.49 & 2.52 & 1.43 & 0.86 & 1.10 & 0.06 & 0.09 & 0.19 & 8.67 \\
\hline
\end{tabular}

En la Figura 9 se presenta la relación entre los escurrimientos y sedimentos anuales simulados con SWAT. Se observó que a mayor precipitación también hay mayor salida de sedimentos de la cuenca. Al respecto, es importante indicar que la baja correlación entre ambas variables podría mejorar si existieran datos de campo para calibrar y validar el modelo útil en la predicción de sedimentos. La cantidad de sedimentos predicha es relativamente baja, lo cual puede deberse a la presencia de las diferentes prácticas, y obras de conservación de suelo y agua presentes en la cuenca, que de acuerdo con Márquez (2013) han reducido la producción de sedimentos de 50184 a 288 toneladas anuales durante el periodo 1961-1990. También Adame-Martínez y MartínezMenes (1999) evaluaron el efecto de las obras de conservación de suelo y agua en la cuenca del río Texcoco y encontraron que éstas redujeron la 
producción de sedimento de 9553 a 0 toneladas para el periodo 19611990.

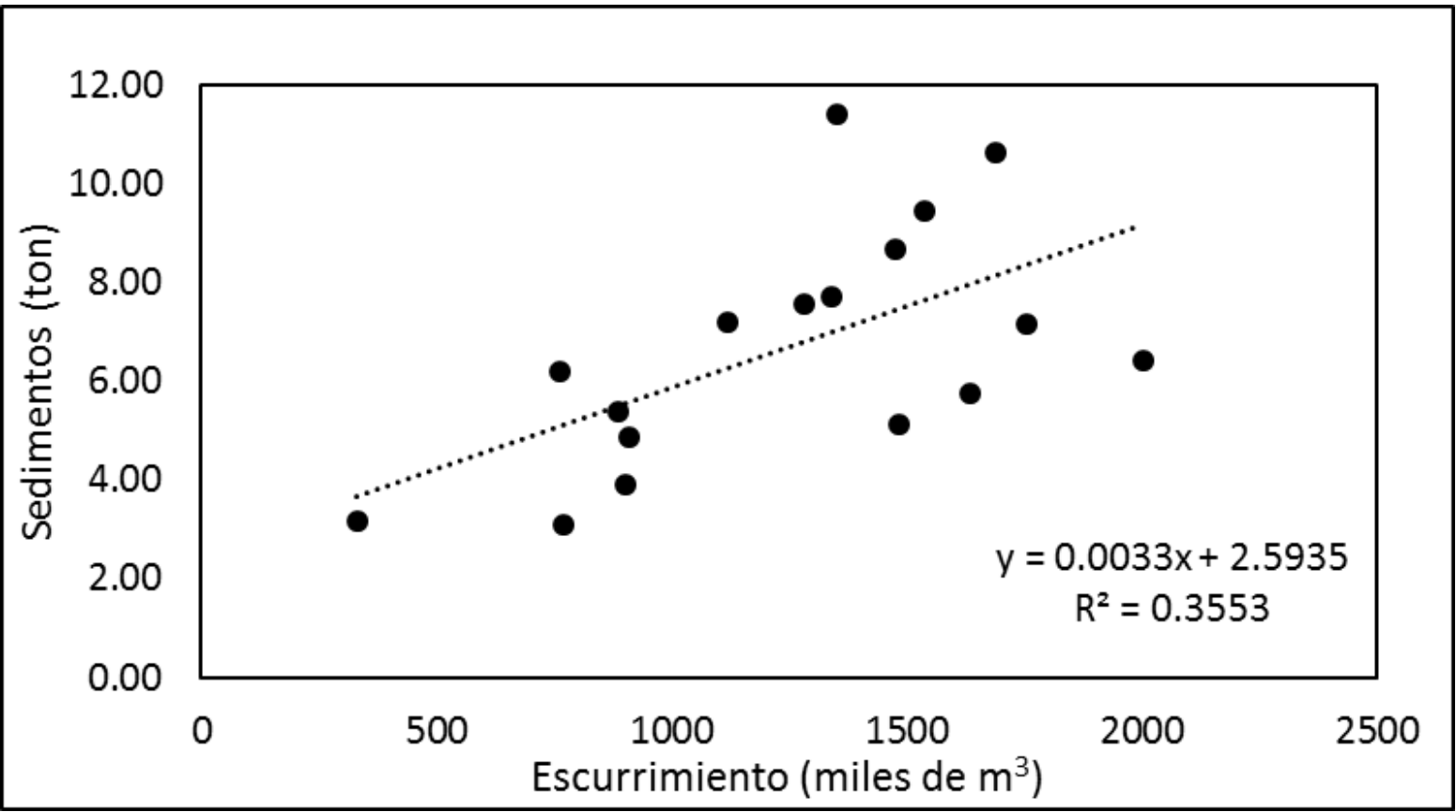

Figura 9. Correlación $(\operatorname{Pr}>F=0.0116)$ entre el escurrimiento y los sedimentos estimados con SWAT que salen de la cuenca del río Chapingo para el periodo 1999-2015.

\section{Comportamiento estadístico de las variables de escurrimiento y sedimento producto del cambio de uso de suelo}




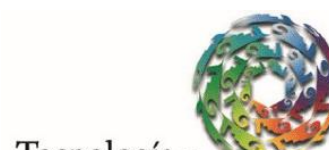

Tecnología y

Ciencias $₫$ Agua
2021, Instituto Mexicano de Tecnología del Agua

Open Access bajo la licencia CC BY-NC-SA 4.0

(https://creativecommons.org/licenses/by-nc-sa/4.0/)

Para determinar si hubo diferencias en las medias mensuales simuladas de escurrimiento y sedimento entre los periodos de estudio (1999-2010 y 2011-2015), en función del cambio de uso de suelo previamente evaluado, primero se realizó una Prueba de $F$ mediante la cual se comprobó la homogeneidad de varianzas (Gómez-Biedma, Vivó, \& Soria, 2001); posteriormente, con una prueba $t$ de student (Di-Rienzo et al., 2009) se compararon dichas medias. Los resultados se presentan en la Tabla 7, donde se observa que el cambio en el uso de suelo no tiene efecto en la cantidad de escurrimiento $(p=0.2351)$ y sedimentos $(p=0.4430)$ de la cuenca del río Chapingo. En general, esto es congruente con los resultados presentados en la Figura 9. Si no cambia el escurrimiento, tampoco se espera que cambie la producción de sedimentos. Asimismo, como se indicó en la sección precedente, se debería considerar que la presencia de prácticas, y obras de conservación de suelo y agua en la cuenca puede estar regulando el escurrimiento y la producción de sedimentos (Márquez, 2013; Adame-Martínez \& Martínez-Menes, 1999).

Tabla 7. Pruebas de $F$ y $t$ de student para las medias mensuales simuladas de escurrimiento y sedimento en función del cambio de uso de suelo (1999-2010 vs. 2011-2015).

Prueba de $\boldsymbol{F}$ para varianza de dos grupos de muestras.

\begin{tabular}{lcc}
\hline & $\begin{array}{c}\text { Escurrimiento } \\
\left(\mathbf{m}^{\mathbf{3}}\right)\end{array}$ & $\begin{array}{c}\text { Sedimentos } \\
(\text { ton })\end{array}$ \\
\hline $\boldsymbol{F}$ & 0.731628556 & 2.12984074 \\
\hline $\boldsymbol{P}(\boldsymbol{F}<=\boldsymbol{f})$ una cola & 0.06897934 & 0.00064802
\end{tabular}


Ciencias $\stackrel{\Xi}{\Im}$ Aua
Valor crítico para $\boldsymbol{F}$ (una cola)
0.707154891
1.45943969

\section{Prueba $t$}

\begin{tabular}{lcc}
\hline Media 1999-2010 & 108505.805 & 0.5628 \\
\hline Media 2011-2015 & 933864.482 & 0.5464 \\
\hline Estadístico $\boldsymbol{t}$ & 0.7249 & 0.1435 \\
\hline $\boldsymbol{P}(\boldsymbol{T}<=\boldsymbol{t})$ una cola & 0.2351 & 0.4430 \\
\hline Valor crítico de $\boldsymbol{t}$ (una cola) & 1.6607 & 1.6544
\end{tabular}

\section{Conclusiones}

El cambio de uso del suelo de la cuenca del río Chapingo para el periodo 1999-2015 se caracterizó por el aumento significativo de las áreas de zona urbana, pastizal y minas; asimismo, por la reducción del área agrícola en $57 \%$. Se encontró una relación entre la disminución del área agrícola y el incremento poblacional.

El modelo SWAT aplicado a la cuenca del río Chapingo en el periodo 1999-2015, con ajuste aceptable (coeficiente Nash-Sutcliffe $=0.52$ ), no detectó cambios significativos en el escurrimiento superficial ( $p=$ 0.2351 ), en función del cambio de uso de suelo y vegetación detectado. 


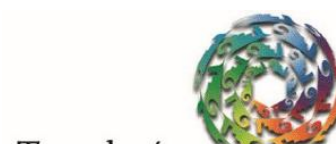

Tecnología y

Ciencias $₫$ Agua
2021, Instituto Mexicano de Tecnología del Agua

Open Access bajo la licencia CC BY-NC-SA 4.0

(https://creativecommons.org/licenses/by-nc-sa/4.0/)

Los coeficientes de Nash-Sutcliffe fueron de 0.58 y 0.52 para la calibración y la validación, respectivamente; se consideran satisfactorios, por lo que el resultado anterior pudo deberse a las condiciones diferentes de la cuenca de estudio respecto a las consideradas en la generación y validación original del modelo.

La dinámica del cambio de uso de suelo no mostró influencia significativa $(p=0.443)$ en los valores promedio mensuales de escurrimiento y producción de sedimento entre los periodos 1999-2010 y 2011-2015; se puede atribuir a que no hubo eventos extremos de precipitación en ninguno de los periodos, y a la presencia de obras y prácticas de conservación de suelo y agua en la cuenca.

La correlación entre el escurrimiento y los sedimentos anuales simulados con SWAT fue significativa $(\operatorname{Pr}>F=0.0116)$, con un coeficiente de determinación bajo $\left(R^{2}=0.36\right)$, resultado atribuible a la falta de datos de campo de sedimentos para calibrar y validar el SWAT para la predicción de éstos.

\section{Agradecimientos}

Al Consejo Nacional de Ciencia y Tecnología (Conacyt) por la beca otorgada para los estudios de Maestría en Ciencia en Hidrociencias, y al Bufete de Ingeniería en Telecomunicaciones y Sistemas, por facilitar el enlace con la plataforma Planet, para la obtención de la imagen RapidEye.

\section{Referencias}




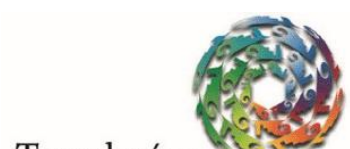

Tecnología y

Ciencias $\stackrel{\Xi}{\simeq}$ Agua
2021, Instituto Mexicano de Tecnología del Agua

Open Access bajo la licencia CC BY-NC-SA 4.0

(https://creativecommons.org/licenses/by-nc-sa/4.0/)

Abbaspour, K. C., Vaghefi, S. A., \& Srinivasan, R. (2018). A guideline for successful calibration and uncertainty analysis for soil and water assessment: A review of papers from the 2016 International SWAT Conference. Water, 10(1), $6 . \quad$ DOI: https://doi.org/10.3390/w10010006

Adame-Martínez, S., \& Martínez-Menez, M. R. (1999). Efecto del manejo integral de la cuenca del río Texcoco, sobre la producción de agua y sedimentos. Investigaciones Geográficas, (39), 53-67.

Almeida, R. A., Pereira, S. B., \& Pinto, D. B. (2018). Calibration and validation of the SWAT hydrological model for the Mucuri River basin. Engenharia Agrícola, 38(1), 55-63. DOI: https://dx.doi.org/10.1590/1809-4430-eng.agric.v38n1p55$63 / 2018$

Behrends, K. F., Chagas, C., Vázquez, A. G., Anselmo, P. E., José, S. O., Castiglioni, M., \& Juan, M. M. (2011). Aplicación del modelo hidrológico SWAT en una microcuenca agrícola de la Pampa ondulada. Suelo (Argentina), 29(1), 75-82.

Bocco, G., Mendoza, M., \& Masera, O. R. (2001). La dinámica del cambio del uso del suelo en Michoacán: una propuesta metodológica para el estudio de los procesos de deforestación. Investigaciones Geográficas, (44), 18-36. Recuperado de http://www.scielo.org.mx/scielo.php?script=sci_arttext\&pid=S018 8-46112001000100003\&lng=es\&tlng=es

Brouziyne, Y., Abouabdillah, A., Bouabid, R., Benaabidate, L., \& Oueslati, O. (2017). SWAT manual calibration and parameter sensitivity analysis in a semi-arid watershed in North-Western Morocco. 


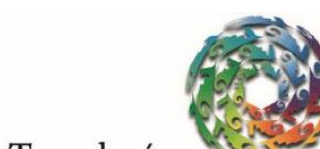

Tecnología y

Ciencias $\stackrel{\Xi}{\simeq}$ Agua
2021, Instituto Mexicano de Tecnología del Agua

Open Access bajo la licencia CC BY-NC-SA 4.0

(https://creativecommons.org/licenses/by-nc-sa/4.0/)

Arabian Journal of Geosciences, 10(427), 1-13. DOI: https://doi.org/10.1007/s1251 7-017-3220-9

Camacho-Sanabria, J. M., Juan-Pérez, J. I., \& Pineda-Jaimes, N. B. (2015). Modeling of land use/cover changes: Prospective scenarios in the State of Mexico. Case study - Amanalco de Becerra. Revista Chapingo Serie Ciencias Forestales y del Ambiente, 21(2), 203-220. DOI: https://doi: 10.5154/r.rchscfa.2014.10.049

Chen, C. (1983). Rainfall intensity-duration-frequency formulas. Revista Ingeniería Hidráulica, 109(12), 1603-1621. DOI: https://doi.org/10.1061/(ASCE)0733-9429(1983)109:12(1603)

Cruz-Huerta, C., González-Guillén, M. J., Martínez-Trinidad, T., \& Escalona-Maurice, M. J. (2015). Modeling land-use change and future deforestation in two spatial scales. Revista Chapingo Serie Ciencias Forestales $y$ del Ambiente, 21(2), 137-156. DOI: https://doi: 10.5154/r.rchscfa.2014.06.025

Di-Rienzo, A., Casanoves, F., González, L. A., Tablada, E. M., Díaz, M., Robledo, C. W., \& Balzarini, M. G. (2009). Estadística para las Ciencias Agropecuarias (7a ed.). Córdoba, Argentina: Editorial Brujas. Recuperado

de http://frrq.cvg.utn.edu.ar/pluginfile.php/2103/mod_resource/cont ent/0/DEPOSITO_DE_MATERIALES/LIBROEST.CIENCIAS.AGRP.UNC._7_Ed.pdf

Díaz, J. J. (2015). Estudios de índice de vegetación a partir de imágenes aéreas tomadas desde UAS/RPAS y aplicaciones de estos a la agricultura de precisión (tesis de maestría). Universidad 


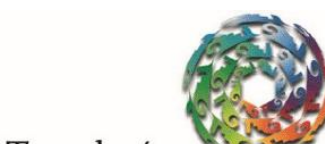

Tecnología y

Ciencias $\stackrel{\Xi}{\simeq}$ Agua
2021, Instituto Mexicano de Tecnología del Agua

Open Access bajo la licencia CC BY-NC-SA 4.0

(https://creativecommons.org/licenses/by-nc-sa/4.0/)

Complutense de Madrid. 147 p. Recuperado de https://eprints.ucm.es/31423/1/TFM_Juan_Diaz_Cervignon.pdf

Ercan, M. B., Goodall, J. L., Castronova, A. M., Humphrey, M., \& Beekwilder, N. (2014). Calibration of SWAT models using the cloud. Environmental Modelling \& Software, 62, 188-196. DOI: https://10.1016/j.envsoft.2014.09.002

ESRI, Environmental Systems Research Institute. (2018). ArcMap 10.4. California, USA. Recuperado de https://desktop.arcgis.com

FAO, Food and Agriculture Organization. (2004). Estudio de tendencias y perspectivas del sector forestal en América Latina al año 2020: Informe Nacional: México. Roma, Italia: Food and Agriculture Organization. Recuperado de https://swat.tamu.edu/media/99192/swat2009-theory.pdf

Fernández, P. C., Acuña, Z. J., Díaz, P. A., \& Felipe, O. O. (2016). Asimilación y evaluación de datos de precipitación en base a satélite en el modelamiento hidrológico de la cuenca del río Vilcanota. Estudio Hidrológico. Lima, Perú: Servicio Nacional de Meteorología e Hidrología del Perú.

García, O., J., Gutiérrez, C., J., \& Balderas, P. M. (2011). Cambio de uso de suelo en una microcuenca del altiplano mexicano. Papeles de Geografía, (53-54), 125-135. Recuperado de http://www.redalyc.org/articulo.oa?id=40721572009

Gómez-Biedma, S., Vivó, M., \& Soria, E. (2001). Pruebas de significación en bioestadística. Revista de Diagnóstico Biológico, 50(4), 207-218. Recuperado de 


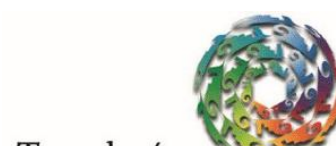

Tecnología y

Ciencias $₫$ Agua
2021, Instituto Mexicano de Tecnología del Agua

Open Access bajo la licencia CC BY-NC-SA 4.0

(https://creativecommons.org/licenses/by-nc-sa/4.0/)

http://scielo.isciii.es/scielo.php?script=sci_arttext\&pid=S003479732001000400008

Gordillo-Ruiz, M., \& Castillo-Santiago, M. (2017). Cambio de uso del suelo en la cuenca del río Sabinal, Chiapas, México. Ecosistemas y Recursos Agropecuarios, 4(10), 39-49. Recuperado de https://dx.doi.org/10.19136/era.a4n10.803

INEGI, Instituto Nacional de Estadística y Geografía. (2018). Página de inicio. Aguascalientes, México: Instituto Nacional de Estadística y Geografía. Recuperado de https://www.inegi.org.mx/

INEGI, Instituto Nacional de Estadística y Geografía. (2000). XII Censo de Población y Vivienda. Aguascalientes, México: Instituto Nacional de Estadística y Geografía. Recuperado de http://www.beta.inegi.org.mx/programas/ccpv/2000/

INEGI, Instituto Nacional de Estadística y Geografía. (2010). Estadística Básica Municipal, Anuario Estadístico del Estado de México (tomo I). Aguascalientes, México: Instituto Nacional de Estadística y Geografía. Recuperado de http://www.inegi.org.mx/contenidos/productos/.../702825200985 -1_1.pdf

Lambin, E. F., Geist, H., \& Rindfuss, R. R. (2006). Introduction: Local processes with global impacts. In: Lambin, E. F., \& Geist, H. J. (eds.). Land use and land cover change. Local processes and global impacts (pp. 1-8). Berlin, Heidelberg: Springer. DOI: https://10.1007/3-540-32202-7_1

Lavagnoli, M., L., Schwamback, D., \& Rigo, D. (2018). Sensitivity analysis of the Soil and Water Assessment Tool (SWAT) model in streamflow 


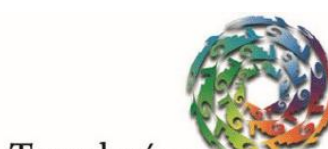

Tecnología y

Ciencias $\stackrel{\Xi}{\unlhd}$ gua
2021, Instituto Mexicano de Tecnología del Agua

Open Access bajo la licencia CC BY-NC-SA 4.0

(https://creativecommons.org/licenses/by-nc-sa/4.0/)

modeling in a rural river basin. Ambiente \& Agua, 13(6). DOI: https://dx.doi.org/10.4136/ambi-agua.2221

Licona-Santana, J., Martínez-Menes, M., Mendoza-Onofre, L., FigueroaSandoval, B., \& Fernández-Reynoso, D. (2006). Uso de modelo EPIC para estimar rendimientos de maíz con base en variables fisiotécnicas en el oriente del Estado de México. Terra Latinoamericana, 24(2), 283-291. Recuperado de http://www.redalyc.org/articulo.oa?id $=57311108016$

López, V. V. H., Balderas, P. M. A., Chávez, M. M. C., Pérez, J. J. I., \& Gutiérrez, C. J. G. (2015). Cambio de uso de suelo e implicaciones socioeconómicas en un área mazahua del altiplano mexicano. CIENCIA ergo-sum, Revista Científica Multidisciplinaria de Prospectiva, 22(2), 136-144. Recuperado de http://www.redalyc.org/articulo.oa?id $=10439327004$

Márquez, Z. J. (2013). Impacto de obras y prácticas de conservación sobre los servicios ambientales hidrológicos de la cuenca del Río Chapingo (tesis de maestría). Colegio de Postgraduados, Montecillo, México.

Mattos, G. S., Parodi, G. N., \& Damiano, F. (2010). Análisis de amenaza por inundación en área urbana empleando modelos hidrodinámicos y herramientas SIG. Buenos Aires, Argentina: Instituto Nacional de Tecnología Agropecuaria. Recuperado de https://inta.gob.ar/sites/default/files/script-tmpanlisis_de_amenaza_por_inundacin_en_rea_urbana_emplea.pdf

Mas, J. F., Velázquez, A., Díaz-Gallegos, J. R., Mayorga-Saucedo, R., Alcántara, C., Bocco, G., Castro, R., Fernández, T., \& Pérez-Vega, 


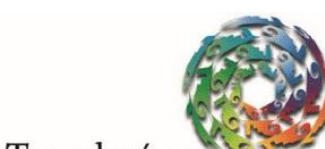

Tecnología y

Ciencias $₫$ Agua
2021, Instituto Mexicano de Tecnología del Agua

Open Access bajo la licencia CC BY-NC-SA 4.0

(https://creativecommons.org/licenses/by-nc-sa/4.0/)

A. (2004). Assessing land use/cover changes: A nationwide multidate spatial database for Mexico. International Journal of Applied Earth Observation and Geoinformation, 5(4), 249-261. DOI: https://doi.org/10.1016/j.jag.2004.06.002

Meneses-Tovar, C. L. (2011). El índice normalizado diferencial de la vegetación como indicador de la degradación del bosque. Unasylva 238, 62(2), 39-46. Recuperado de http://www.fao.org/3/i2560s/i2560s07.pdf

Miranda, A. L. (2008). Dinámica de uso del suelo y su efecto en el escurrimiento superficial en la cuenca del río Grande, Tlalchapa, Guerrero (tesis de maestría). Colegio de Postgraduados, Montecillo, México.

Morales-Hernández, J. C., Carrillo-Gonzales, F. M., Zarfán-Molina, L., \& Cornejo-López, V. M. (2016). Cambio de cobertura vegetal en la región de Bahía de Banderas, México. Revista Colombiana de Biotecnología, 18(1), 7-16. DOI: http://doi: 10.15446/rev.colomb.biote.v18n1.57709

Moreno-Sánchez, E. (2013). Texcoco en lo sociourbano y económico. Periodo 2000-2012. Quivera. Revista de Estudios Territoriales, 15(2), 63-92. Recuperado de http://www.redalyc.org/articulo.oa?id=40128974005

Neitsch, S. L., Arnold, J. G., Kiniry, J. R., \& Williams, J. R. (2009). Soil and water assessment tool theoretical documentation version (2009). Temple, USA: Blackland Research Center, Texas Agricultural Experiment Station. Recuperado de https://swat.tamu.edu/media/99192/swat2009-theory.pdf 


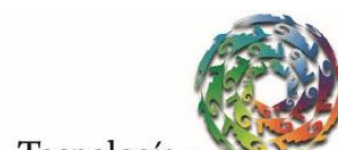

Tecnología y

Ciencias $₫$ Agua
2021, Instituto Mexicano de Tecnología del Agua

Open Access bajo la licencia CC BY-NC-SA 4.0

(https://creativecommons.org/licenses/by-nc-sa/4.0/)

Ojeda, T. E. (2001). Gis and land use in Texcoco municipality, México: contrasting local and official understandings (Doctoral thesis, Department of Geography). Durham University. Recuperado de http://etheses.dur.ac.uk/3854/

Palacio-Prieto, J. L., Sánchez-Salazar, M. T., Casado, J. M., Propin, F., E., Delgado, C. J., Velázquez, M. A., \& Camacho, R. C. G. (2004). Indicadores para la caracterización y el ordenamiento territorial. México: Semarnat. Recuperado de https://www.researchgate.net/publication/288840782_Indicadores _para_la_Caracterizacion_y_Ordenamiento_del_Territorio

Planet. (2018). Daily Satellite Imagery and Insights. San Francisco, California, USA. Recuperado de https://www.planet.com/

Ramírez, C. H., López, V. O., \& Ibáñez, C. L. A. (2015). Estimación mensual de intensidad de la lluvia en 30 minutos a partir de datos pluviométricos. Terra Latinoamericana, 33(2), 151-159. Recuperado de https://www.redalyc.org/articulo.oa?id=573/57339210005

Rodrigues, S. V., Tavares, S. M., Singh, P. V., Pereira, S. E., Campos, B. C., Morant, H. R., Silveira, R. A., Salviano, S. F., \& Rodrigues, B. A. (2017). Simulation of stream flow and hydrological response to land-cover changes in tropical river basin. Catena, 162, 166-176. DOI: https://doi.org/10.1016/j.catena.2017.11.024

Salas-Martínez, R., Ibáñez-Castillo, L., Arteaga-Ramírez, R., MartínezMenes, M., \& Fernández-Reynoso, D. (2014). Modelado hidrológico de la cuenca del río Mixteco en el estado de Oaxaca, México. Agrociencias. $\quad 48(1)$ 1-15. Recuperado de 


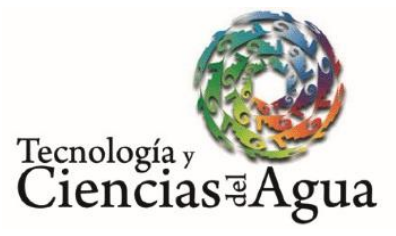

2021, Instituto Mexicano de Tecnología del Agua

http://www.scielo.org.mx/scielo.php?script=sci_arttext\&pid=S140 $5-31952014000100001 \& \operatorname{lng}=e s \&$ tIng $=e s$

Sánchez-Galindo, M., Fernández-Reynoso, D., Martínez-Menes, M., Rubio-Granados, E., \& Ríos-Berber, J., D. (2017). Modelo hidrológico de la cuenca del río Sordo, Oaxaca, México, con SWAT. Tecnología y ciencias del agua, 8(5), 141-156. DOI: https://doi.org/10.24850/j-tyca-2017-05-10

Teklay, A., Dile, Y. T., Setegn, S. G., Demissie, S. S., \& Asfaw, D., H. (2019). Evaluation of static and dynamic land use date for watershed hydrologic process simulation: A case study in Gummara watershed, Ethiopia. Catena, 172, 65-75. DOI: https://doi.org/10.1016/j.catena.2018.08.013

Torres-Benites, E., Fernández-Reynoso, D., Oropeza-Mota, J., L., \& MejíaSaenz, E. (2004). Calibración del modelo hidrológico SWAT en la cuenca "El Tejocote", Atlacomulco, Estado de México. Terra Latinoamericana, 24(4), 437-444. Recuperado de http://www.redalyc.org/articulo.oa?id=57311096007

Trucios, C. R., Martínez, R. J., Blando, N. J., \& Sánchez, C. I. (2007). Calibración y validación del modelo hidrológico SWAT en la cuenca del río Sextín en Durango, México. Revista Chapingo Serie Zonas Áridas, 6, 91-101. Recuperado de http://www.redalyc.org/articulo.oa?id $=455545068010$

USGS, United States Geological Survey. (2018). Earth Explorer. Reston, USA. Recuperado de https://www.usgs.gov/

Vargas-Castañeda, G., Ibáñez-Castillo, L., \& Arteaga-Ramírez, R. (2015). Development, classification and trends in rainfall-runoff modeling. 
Ingeniería Agrícola y Biosistemas, 7(1), 5-21. DOI: http://dx.doi.org/10.5154/r.inagbi.2015.03.002

Wischmeier, W. H., \& Smith, D. D. (1978). Predicting rainfall erosion losses-A guide to conservation planning. Washington, DC, USA: USDA. Recuperado de https://naldc.nal.usda.gov/download/CAT79706928/PDF

Zhang, S., Fan, W., Li, Y., \& Yi, Y. (2017). The influence of changes in land use and landscape patterns on soil erosion in a watershed. Science of the Total Environment, 574(1), 34-45. DOI: https://doi.org/10.1016/j.scitotenv.2016.09.024 